\title{
Do practice weights vary from wrestling weights throughout the season and can the difference predict win/loss records?
}

\author{
Rebecca L. Sidener \\ West Virginia University
}

Follow this and additional works at: https://researchrepository.wvu.edu/etd

\section{Recommended Citation}

Sidener, Rebecca L., "Do practice weights vary from wrestling weights throughout the season and can the difference predict win/loss records?" (2004). Graduate Theses, Dissertations, and Problem Reports. 1998. https://researchrepository.wvu.edu/etd/1998

This Thesis is protected by copyright and/or related rights. It has been brought to you by the The Research Repository @ WVU with permission from the rights-holder(s). You are free to use this Thesis in any way that is permitted by the copyright and related rights legislation that applies to your use. For other uses you must obtain permission from the rights-holder(s) directly, unless additional rights are indicated by a Creative Commons license in the record and/ or on the work itself. This Thesis has been accepted for inclusion in WVU Graduate Theses, Dissertations, and Problem Reports collection by an authorized administrator of The Research Repository @ WVU. For more information, please contact researchrepository@mail.wvu.edu. 
Do practice weights vary from wrestling weights throughout the season and can the difference predict win/loss records?

Rebecca L. Sidener, BS, ATC

Thesis submitted to the School of Physical Education at West Virginia University in partial fulfillment of the requirement for the degree of

\author{
Master of Science \\ in \\ Athletic Training
}

Michelle A. Sandrey, Ph.D., ATC, Chair

Kevin Kotsko, MEd, ATC

Edward Etzel, Ph.D

Sam Zizzi, Ph.D

Department of Athletic Training

Morgantown, West Virginia

2004

Keywords: weight-cycling, wrestling, performance

Copyright 2004 Rebecca L. Sidener 


\begin{abstract}
Do practice weights vary from wrestling weight throughout the season and can the difference predict win/loss records?

By Rebecca Lynne Sidener

Context: The common practice of rapid weight loss in wrestling has been well
\end{abstract} documented throughout the literature since the 1930's. Prior to 1997, many wrestlers would lose 10-12 lbs in as few as 3-4 days before a wrestling match. After the tragic deaths of 3 collegiate wrestlers, the National Collegiate Athletic Association (NCAA) implemented rule changes to prevent further tragedies. Objective: The purposes of this study was to determine if weight fluctuates between two time points from the competition weight; 2) if the wrestlers who lose the least amount of weight throughout the entire season had a different win percentage than those who lost more weight. Design: This study was a longitudinal comparative study. The independent variables were competition weights and time for the first purpose. The dependent variable was the average weight deviation. The independent variable was the average weight deviation at the two time points (two variables) and the dependent variable was the win percentage for the second purpose. Setting: The study took place at West Virginia University, Eastern Wrestling League universities, and other Division I institutions on the West Virginia University schedule. Patients or Other Participants: Twenty-two male NCAA Division 1 wrestlers between the ages of 19 and 23 volunteered for this study. Of the 22 original subjects, 13 subjects were included for data analysis. Subjects were excluded from the study if they did not participate during the regular season competition or if they were injured for 4 consecutive weeks without the ability to participate in team conditioning, lifting, or practice. Interventions: Practice weights were measured on Monday and Wednesday after regular practice. Competition weights were recorded at regular season tournament and dual meets. A survey was administered at the end of the data collection period to the final participants. Main Outcomes Measure: The investigator felt there would be a greater weight deviation away from the competition weight during the $1^{\text {st }} 8$ week period compared with the $2^{\text {nd }} 8$ week period. Also, the investigator felt there would be an increased win percentage in the individuals who had a lower weight deviation from their competition weight. Results: The average weight deviation for the $1^{\text {st }} 8$ weeks was $5.1909 \pm 2.13 \mathrm{lbs}$ and the win percentage average was $60.88 \% \pm .20$. There was no significant correlation between average weight and win percentage $(\mathrm{r}=-.282, \mathrm{P}=.401)$. The average weight deviation for the $2^{\text {nd }} 8$ weeks was $3.93 \pm 2.83$ and the win percentage average was $56.8 \%$. There was no significant correlation between the two variables $(\mathrm{r}=$ $.121, \mathrm{P}=.693)$. There was no significant differences between groups for the $1^{\text {st }} 8$ weeks $\left(\mathrm{t}_{9}=-.327, \mathrm{P}=.75\right)$ and the $2^{\text {nd }} 8$ weeks $\left(\mathrm{t}_{11}=-1.457, \mathrm{P}=.173\right)$. Conclusion: The results of this study show that the average weight deviation did not significantly change from the $1^{\text {st }}$ 8 weeks to the $2^{\text {nd }} 8$ weeks. Also, there was no correlation between those wrestlers that lost the least amount of weight and win percentage. Further, there was no difference between the wrestlers that had a win percentage $>50 \%$ than the wrestlers that had a win percentage $\leq 50 \%$ for average weight deviation.

Key Words: win percentage, wrestling, rapid weight loss 


\section{AKNOWLEDGMENTS}

First, I would like to thank my family and friends for their steadfast love and support. Without their encouragement, patience, and support, I would never have completed this momentous task. I will always remember their kind words and everlasting confidence in my ability to finish this task. There are not enough words to tell them how much they mean to me. Suffice it to say I love them all very, very much.

Without the support of the wrestlers and coaching staff I would not have been able to do this study at all. I must thank the wrestlers for their patience in weighing-in every Monday and Wednesday and for letting me track their personal weights for such a long time. Also, the wrestling coaches who constantly made every day an interesting experience for me during the two years I worked with them.

I would like to thank Dr. Sandrey for enabling me to do a study I was not only required to do but that I was interested in. She helped me from the early stages of all my ideas to the final stages before my defense. She has always had her door open if I needed help and was willing to talk about my questions.

Without the help of Kevin Kotsko MEd, ATC, this study may never have begun. I would like to thank him for being an inspirational role model and mentor during my two years here at West Virginia University. I have never met a harder-working individual. He strived to make my time here enjoyable while making sure I was challenged daily to learn new concepts. He has been instrumental in my learning in ways he didn't even realize. I shall always be grateful for his guidance.

I would like to thank Dr. Etzel for helping me realize no event or task is too stressful and to take time to relax. Also, he made me understand the importance of sitting down and reviewing the situation calmly instead of rushing into a problem. Dr. Etzel was always willing to sit in his office and go over draft revisions or just listen to any problems I was having with my study.

As with most students who cross his path, I am indebted to Dr. Zizzi for his immense knowledge of statistics, and most importantly, SPSS. Luckily, I was able to form a tight bond with SPSS and we didn't have too many problems but without Dr. Zizzi, none of this would be possible. Also, I would like to thank him for his patience in explaining to me the best statistical option for this complicated data set. He made my job so much easier.

Finally, I would like to thank the athletic training staff and the athletic training students for helping me in anyway possible for these last two years. The staff was willing to help me whether it was with job hunting or athletic training related issues. The students have also helped me become more proficient in my own proficiencies throughout my time as an ACI. 


\section{TABLE OF CONTENTS}

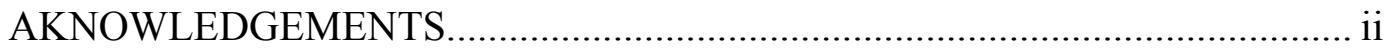

LIST OF TABLES .............................................................................. iv

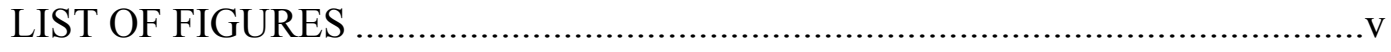

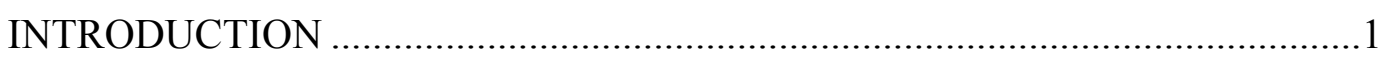

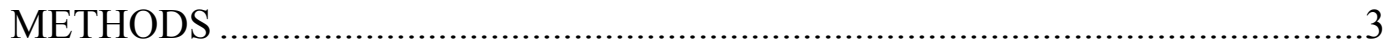

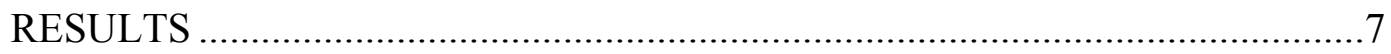

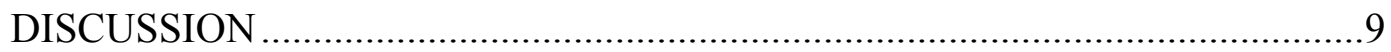

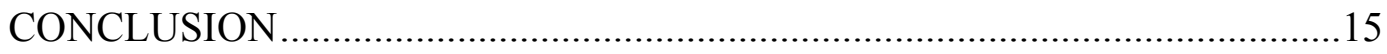

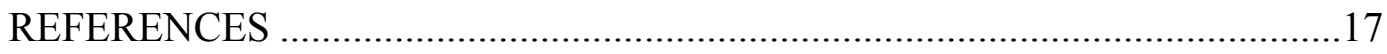

APPENDICES

A. THE PROBLEM ........................................................................21

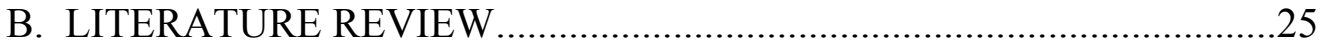

C. ADDITIONAL METHODS ...............................................................43

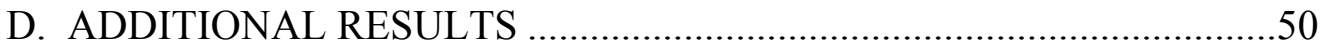

E. RECOMMENDATIONS FOR FUTURE RESEARCH ..........................53

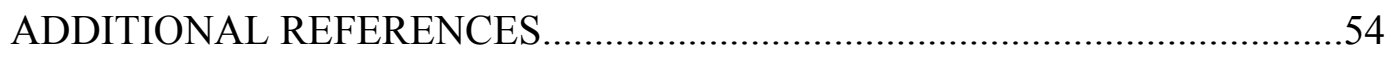




\section{LIST OF TABLES}

Table

B1. Effects of Weight Cutting on Physiological Performance .............................39

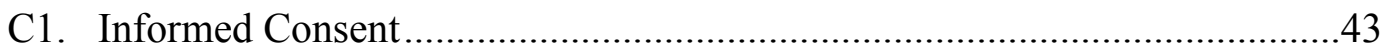

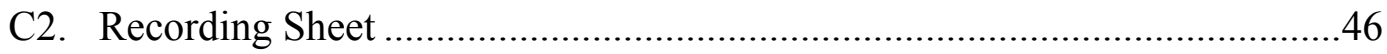

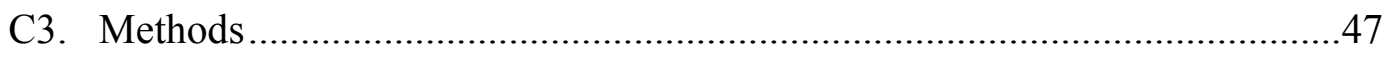

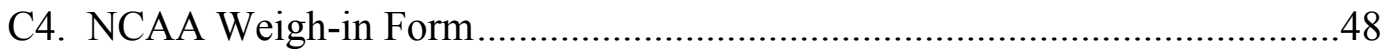

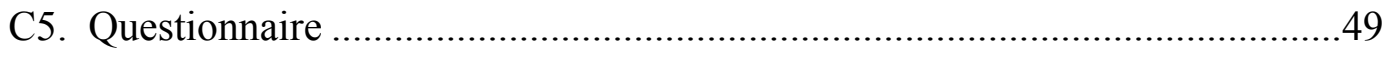

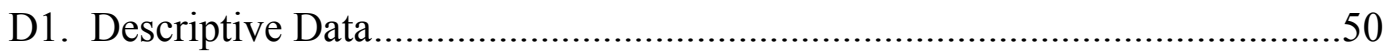

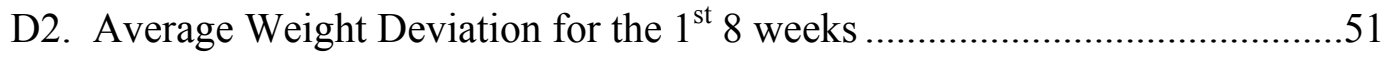

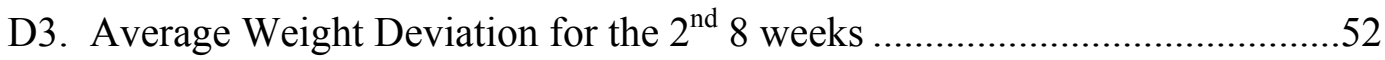




\section{LIST OF FIGURES}

Figure

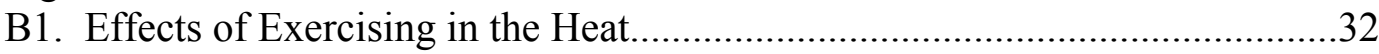




\section{INTRODUCTION}

Historically, wrestling coaches and athletes have believed it was necessary for a wrestler to compete at a weight class below their normal weight in order to gain a competitive edge over their opponent. ${ }^{1}$ Specifically, it is assumed that the athletes' gain strength, increase speed and reaction time, and due to larger and taller statures, the athletes' have greater leverage than their counterpart. ${ }^{1,2,3}$ This belief has caused countless adolescents and young adult males to use harmful and potentially lifethreatening rapid weight loss (RWL) methods. ${ }^{4}$ Harmful weight loss techniques such as the use of laxatives, diuretics, fasting, steam rooms, saunas, and rubber suits have been identified and subsequently prohibited by the National Collegiate Athletic Association (NCAA) because of the potential pathological affects associated with these practices. Athletes who engage in RWL attempted to lose 10-12 pounds of body weight 3-4 days before a match in order to have an advantage over their opponents. ${ }^{1-3,5-9}$ The detrimental nature of these practices was brought to light when three Division I collegiate wrestlers died in $1997 .{ }^{10}$ After these incidents, the NCAA implemented changes to hold athletes, coaches, and the athletic training staff more responsible for controlling the amount of weight lost during the preseason and season. ${ }^{11,12}$

Recommendations for weighing in athletes throughout the season have been made by the NCAA, National Athletic Trainers' Association (NATA), and the American College of Sports Medicine (ACSM). However, these weigh-in guidelines are more specifically associated with heat illness and dehydration than RWL in wrestling. Both the NATA and the NCAA state that athletes should be weighed in before and after 
practice to monitor the amount of water loss during practice. ${ }^{13,14}$ If the athlete has a weight loss of $5 \%$ of their body weight, there may be a risk for dehydration.

Excessive weight loss in wrestlers can cause severe health problems that may have serious effects on the cardiovascular system $(\mathrm{CV})$, thermoregulatory responses, renal function, immunosuppression ${ }^{15}$, and athletic performance. $1,9,16,17,18,19,20,21,22,23$ When coupled with intense exercise, dehydration ${ }^{17,19,21,24,25}$ will decrease performance capacity due to the heart rate being unable to compensate for the larger decreases in stroke volume. ${ }^{18}$ During dehydration, there is a decrease in plasma volume which limits oxygen transportation. With decreased oxygen levels, the athlete will be unable to sustain prolonged exercise. ${ }^{21}$ However, when exercise is prolonged for 5-24 hours after hydration and caloric intake, anaerobic performance is typically unchanged. ${ }^{21,26}$ Horswill et al. ${ }^{24}$ reported that when wrestlers are exposed to high carbohydrate diets the total sprint work performed was higher than the lower carbohydrate diets. However, both results were decreased from baseline measurements.

Armstrong et al. ${ }^{27}$ observed a decreased performance in aerobic running events and a significant decrease in anaerobic capacity during RWL. Currently, anaerobic performance has been shown to both decrease and remain the same during rapid weight loss. ${ }^{21,25}$ Other studies ${ }^{3,5,16,24}$ have noted that mood, cognitive performance, and eating patterns can be affected by RWL.

Changes in power, speed, and strength during dehydration have been reported. ${ }^{7,21,}$ 25, 26, 28-30 Aerobic performance and upper body strength declined after dehydration with diet and exercise ${ }^{21,25}$, or other weight loss techniques. ${ }^{25,26}$ Schmidt et al. ${ }^{29}$ found that both acute and chronic dehydration yielded a decrease in high power exercise 
performance, while only a few significant differences in muscular strength and endurance were noted $^{7}$. Short periods often available by wrestlers to re-hydrate before matches do not appear effective in returning anaerobic performance to baseline before competition. ${ }^{21}$, 26, 30

There has been extensive research on the relationship between RWL, power, strength, endurance, dehydration and how it relates to the sport of wrestling. $6,7,21,25,26,29$, ${ }^{30}$ However, these studies have all been experimental reports with laboratory controls and protocols requiring in a relatively short time span. None of these experiments have looked at the relationship between RWL and win percentages during the wrestling season. The efficacy of RWL and success in sport is not well documented. ${ }^{31}$ Currently, there is little research on the relationship between RWL and win percentages in wrestling competition. Therefore, the two purposes of this study was to determine 1) if average weight fluctuated during two different time points from the competition wrestling weight; 2) if the wrestlers who lose the least amount of weight throughout the entire season had a different win percentage than those who lost more weight.

\section{METHODS}

This study-was a longitudinal comparative design to analyze the data during two time points (Nov.17, 2003-Jan. 9, 2003 and Jan 10, 2004-March 7, 2004). The first question's independent variable was time $\left(1^{\text {st }}\right.$ and $2^{\text {nd }} 8$ weeks $)$ and competition weight. The dependent variable was the average range of weight deviation. The second question had two independent variables of the average range above the competition weight at the $1^{\text {st }}$ and $2^{\text {nd }} 8$ week time points. The dependent variable was the win percentage of each wrestler. 
Subjects

This study started with 22 volunteer Division I collegiate wrestling athletes (mean age $21 \pm 1.04)$. Of the final subjects $(n=13), 46 \%(n=6)$ were juniors, $38.5 \%(n=5)$ were seniors, and sophomores and freshmen accounted for $7.7 \%$ each $(n=2)$. The competition weight of the wrestlers ranged from $125 \mathrm{lbs}$ to $285 \mathrm{lbs}$. Subjects were recruited from the University wrestling team using convenience sampling. Subjects were excluded if they sustained an injury during practice or competition that did not allow them to participate for 4 consecutive weeks or if they did not wrestle at all competitively. A subject was able to continue to participate in the study when injured if they could shadow wrestle, perform aerobic or anaerobic workouts, or be involved in weight training. One subject was excluded from the study because he sustained an injury that did not allow him to participate in activity. Eight other subjects were excluded because they failed to wrestle in any event for the team. Subjects all read and signed a written consent form approved by the university before beginning the study (Table C1). The study was approved by University's Institutional Review Board.

Instrument

Weight measurements were taken on an industrial sized digital scale; Panther (Mettler, Toledo, $\mathrm{OH}$ ). The scale is accurate to the $0.1 \mathrm{lb}$. The scale is calibrated yearly by Kanawha Scales \& Systems (Fairmont, WV) as per manufactures and NCAA specifications. The calibration procedure requires the technician to empty the scale platform and then press enter on the digital scale. Test weights are then placed on the scale platform in increments of 50lbs (beginning with 50lbs and ending with 500lbs). 
The weight value is entered one at a time and the procedure is repeated until 500lbs is on the scale.

Procedures

The purpose of the study was described at the initial meeting with the subjects. After the subjects signed the informed consent form indicating their willingness to be in the study, they were informed that if they met the criteria, they were to report for the first day of the study where weights were recorded (Table C2). During the weigh-in procedure (Table C3), the weight recorder asked the athlete to disrobe. The nude athlete then got on the scale and placed his back toward the scale reading. The athlete was then asked to place his feet at the exact middle of the scale. The athlete placed his hands at his sides and stood still on the scale. The examiner was on the left side of the athlete reading the scale output. The weight was recorded from the digital scale to the tenth of a pound on the data collection sheet. The weigh-ins took place on Mondays and Wednesdays of each week for the specified two time periods. The competition weights (Table C4) that were taken during the two time periods were also included with the practice weights. All wrestlers were identified by a code at the weigh-in. At the conclusion of the study, the final 13 subjects participating in the study completed a confidential and coded demographic questionnaire (Table C5), which was used for descriptive analysis. Data Analysis

Data was collected at the beginning of the regular season (Nov. 17, 2003 - Jan. 09, 2004) and the end of the regular season (January 09, 2004 - March 7, 2004). Data obtained from the weigh-ins were entered in a spreadsheet depicting the two time periods of practice weights over time and competition weights. Average weight deviation was 
calculated using the following equation: [(Practice weight (Monday) + Practice weight $($ Wednesday))/2] - competition weight. Next, total wins and total losses for each week were added into the data spreadsheet. The average weight deviation for the first eight weeks was determined by the equation: (average weight deviation for week $1+3+7+8$ )/4. Weeks 2, 4, 5, and 6 were left out of the equation because the wrestlers had no practice those weeks or there was no competition during that week to compare weights. The average weight deviation for the second eight weeks was determined by the equation: (average weight deviation for week $9+10+12+13+14+16$ )/6. This equation did not include weeks 11 and 15 because the wrestlers were either off that week or there was no competition that week. The average win percentages for the first eight weeks used the following equation: (total wins/total matches)x100. Determination of the average win percentage for the second eight weeks used the same equation: (total wins/total matches)x 100. Information about total wins and total matches was obtained from the sports information director. The wrestlers were then grouped into those above $50 \%$ win percentage and those below 50\% win percentage.

Statistical Analysis

Descriptive statistics (means and standard deviations) were calculated for the demographic information collected for all subjects. A one-way repeated measures Analysis of Variance (ANOVA) was used for the first design in order to assess the two time periods of practice and competition weights over time. Simple main effects testing were used to identify where the significant differences existed between time points. Two independent t-tests were performed to determine if there was a significant difference between groups. The $\mathrm{P}$ value for all three tests was $\mathrm{P} \leq .05$. The original statistical 
analysis used a one-way repeated measures ANOVA to assess the two time periods of practice and competition weight over time was not used. After the data was collected and placed into the spreadsheet, it was determined that a Pearson's Correlation was better suited for the statistical analysis due to the missing weeks. The $\mathrm{P}$ value still remained at $\mathrm{P} \leq .05$. Analyses were performed using SPSS for Windows statistical software (version 11.0.0, SPSS. Inc., Chicago, IL).

\section{RESULTS}

\section{Demographic Information}

There were 5 wrestlers who had 2 years of eligibility left and another 5 had 1 year of eligibility left (38.5\% each), 15.4\% $(n=2)$ had no years of eligibility left, and $7.7 \%$ $(n=1)$ had 3 years of eligibility left. Approximately $46.2 \%(n=6)$ of the subjects had wrestled in their present weight class for 1 year. Seven and seven tenths percent $(n=1)$ had wrestled in his present weight class for 2 years, $23.1 \%(n=3)$ had wrestled for 3 years in the present weight class, another $7.7 \%(n=1)$ had wrestled in his weight class for 4 years, and $15.4 \%(\mathrm{n}=2)$ had wrestled in their present weight class for 5 years. The wrestlers that participated in the survey, $46.2 \%(n=6)$ had changed weight classes by moving up in weight class. The other 7 subjects had not changed weight classes in the past year. The majority of the subjects $(14.77 \pm 2.68)$ reported they had wrestled for 15 or more years. Sixty one and five tenths percent $(n=8)$ of the subjects are on a partial scholarship, $7.7 \%(n=1)$ were on a quarter, and 7.7\% $(n=1)$ full scholarship, and $23.1 \%$ $(n=3)$ of the subjects were on no scholarship. Of the subjects, only $15.4 \%(n=2)$ were walk-on athletes. 
During the off-season, the subjects estimated on average they consumed somewhere between $1500-4000$ calories per day. The majority $38.5 \%(n=5)$ of the subjects reported that they consume 4000 calories per day. During the regular season the range of caloric intake was dramatically different with a range of 850-3500 calories per day. Twenty three and one tenth percent $(n=3)$ reported consuming an estimated 2000 calories per day, while another $23.1(n=3)$ consumed approximately 2500 calories per day. The subjects lost anywhere from $81 \mathrm{bs}-11 \mathrm{lbs} ; 3,2$, or 1 day before a match. (Table D1) Approximately $31 \%(n=4)$ of the subjects estimated their total weight fluctuation to be about $10 \mathrm{lbs}$ between matches. The majority of the wrestlers exercise approximately 4-5 days per week during the preseason $(46.2 \%, n=6)$, with the range being $2-7$ days per week. During the regular season, approximately $77 \%(n=10)$ of the subjects exercised 25 times extra (not during a scheduled team practice). During the off-season approximately $77 \%(n=10)$ of the subjects exercised $2-4$ days. Average Weight Deviations and Win Percentages for the Two Time Periods The average weight deviation for the $1^{\text {st }} 8$ weeks time period was calculated and correlated with the $1^{\text {st }} 8$ week win percentage average. The average weight deviation for the $1^{\text {st }} 8$ weeks was $5.1909 \pm 2.13 \mathrm{lbs}$. The win percentage average was $60.88 \% \pm .20$. There was no significant correlation between the two variables (average weight and win percentage $) \quad(\mathrm{r}=-.282, \mathrm{P}=.401)$. This calculation was then repeated for the $2^{\text {nd }} 8$ weeks time period for both average weight deviation and win percentage. The average weight deviation for the $2^{\text {nd }} 8$ weeks was $3.93 \pm 2.83$ and the win percentage average was $56.8 \%$. Again, there was no significant correlation observed between the two variables $(r=-.121$, $\mathrm{P}=.693)$. 
Win Percentages for the Two Time Periods

Subjects were then grouped into those that had a win percentage $\leq 50 \%$ and those with a win percentage $>50 \%$. In the $1^{\text {st }} 8$ weeks, there were 4 subjects with a win percentage $\leq 50 \%$ and 7 subjects with a win percentage $>50 \%$. In the $2^{\text {nd }} 8$ weeks, there were 4 subjects with win percentages $\leq 50 \%$ and 9 wrestlers with win percentages $>$ $50 \%$. The independent $t$-tests for the $1^{\text {st }}$ and $2^{\text {nd }} 8$ weeks were not significant $\left(t_{9}=-.327\right.$, $\mathrm{P}=.75)$ and $\left(\mathrm{t}_{11}=-1.457, \mathrm{P}=.173\right)$, respectively.

\section{DISCUSSION}

The first hypothesis of this study stated there was a difference between average weight deviation and competition weight during two different time points. The results of the study indicated there was a small difference in average weight deviation for the $1^{\text {st }} 8$

week time period $(5.1901 \pm 2.13)$ and the $2^{\text {nd }} 8$ week time period $(3.93 \pm 2.83)$. Although there was a difference, this was not significantly significant; therefore, the hypothesis was rejected. The second question in the study stated the wrestlers that lose the least amount of weight throughout the season would have a better overall win percentage than those subjects with a higher average weight deviation. Again, this was not statistically significant; therefore, the hypothesis was rejected.

Demographic Information

Anecdotal evidence was noted during the 16-week study period. Remarkably, the two individuals who had the most weight change from the $1^{\text {st }} 8$ week average weight deviation to the $2^{\text {nd }} 8$ weeks average weight deviation also complained of fatigue the most. During a match, the wrestlers' body uses primarily the anaerobic system. It is not wrong to say that the sport has an aerobic component either as the activity must be kept at 
a high level of intensity throughout the duration of the match. The two subjects also complained of slower movements during matches and reported inability to finish the match without feeling completely exhausted and unable to "move their legs." Often the wrestlers used the word "dead legs" to describe their symptoms. Also, these wrestlers reported they exercised 6-7 times per week in addition to their regularly scheduled practices. During some weeks, two-a-day practices would be held.

The fatigue symptoms experienced by these athletes after RWL is not uncommon. Glycogen levels can sometimes cause glycogen depletion to be decreased to $29 \%$ after the first 48 hours with an additional 25\% decrease after another 48 hours during "making weight." ${ }^{6}$ Thus indicating that premature fatigue could result in poor performance. This finding coincides with the statements the subjects made about their symptoms of fatigue, and could explain why the athletes occasionally report fatigue type symptoms in their legs before and after matches.

Upper body strength ${ }^{25,26}$ may also be affected by RWL. A study by Hickner et $\mathrm{al}^{25}$ found that there was a decrease in upper body power output. This could be explained by the decrease in caloric intake; which causes a reduction in muscle glycogen stores. Without the necessary nutrients and energy for muscles to work the adverse effect becomes fatigue; this in turn affects performance outcomes. An increase in muscle glycogen as noted in previous studies, ${ }^{28,32,33}$ to delay fatigue in aerobic and anaerobic capabilities, upper body strength, and endurance performance should be encouraged.

The subjects were asked in the demographic study to estimate how many pounds they tend to lose 3,2, and 1 day(s) before a match. The majority of the athletes lost 5lbs, 3 days before a match; $31 \mathrm{bs}, 2$ days before a match; and 1lb, 1 day before a match. These 
weight changes contrast sharply to what other literature reports. While some studies $2,3,6$, $7,8,9$ have indicated that a few wrestlers attempt to lose 10-12lbs 3-4 days before a match. Oppliger et al. ${ }^{3}$ reported a range of weight loss that was 6.82-9.9lbs weekly. These results by Oppliger et al. ${ }^{3}$ are more closely related to this analysis. It is interesting that of the studies $2,3,6,7,8,9$ that listed the weight loss to be $10-12$ lbs weekly were all completed well before the rule changes of 1997. More recent literature ${ }^{11}$ published in 2001 reviewed the NCAA changes made in 1997 and determined the new NCAA program supported the improvement in the overall health characteristics of the wrestlers. Research by Song and Cipriano ${ }^{34}$ reported significantly lower fat free mass (FFM) compared to the preseason when the wrestlers used weight cycling methods. However, the study performed by Utter ${ }^{11}$, found a significantly decreased amount of fat mass rather than FFM after the NCAA changes were implemented. It is important the athlete lose fat mass instead of FFM because the wrestler is then losing unneeded fat instead of muscle tissue.

The results in this study is consistent with Utter's ${ }^{11}$ finding in that there was not a significant amount of average weight deviation. This finding is encouraging in that it supports the NCAA rule changes that compel athletes, athletic trainers, and coaches, to begin the weight loss program early, making it healthier for the athletes to certify at the appropriate weight class. Allowing the athlete to certify at a weight that is closer to his natural weight, decreases the potential harmful effects of RWL. Win Percentages for the Two Time Periods

A correlation was calculated between the $1^{\text {st }} 8$ weeks and win percentage for the $1^{\text {st }} 8$ weeks. Another correlation for the $2^{\text {nd }} 8$ weeks and the win percentage for the $2^{\text {nd }} 8$ 
weeks indicated no statistical relationship (Table D2). Although there was no statistical difference between the two time periods, there were individual subject differences that should be further examined. One subject's $1^{\text {st }} 8$ week average weight deviation was a change of $8.931 \mathrm{bs}$ while his $2^{\text {nd }} 8$ week change was only $4.761 \mathrm{bs}$. Another subject had a $1^{\text {st }} 8$ week weight deviation of $6.75 \mathrm{lbs}$ whereas his $2^{\text {nd }} 8$ week average weight deviation was only $2.67 \mathrm{lbs}$. Finally, one subject had a $1^{\text {st }} 8$ average week weight deviation of $7.70 \mathrm{lbs}$ and his $2^{\text {nd }} 8$ weeks average weight deviation of $2.85 \mathrm{lbs}$. Of the 3 subjects who had the most weight deviation in the $1^{\text {st }} 8$ weeks, only 1 subject's win percentage was significantly affected.

The subject who had the greatest change of average weight deviation had his weight class changed during the season due to medical reasons. Originally, the subject certified at the beginning of the season 2 weight classes below what he wrestled last year but due to medical complications from his diet, his physician informed him he had to move up to his original weight class or higher or risk severe medical problems. This is important to investigate because during his $1^{\text {st }} 8$ week win percentage when he had an average deviation of $7.70 \mathrm{lbs}$ he had a win percentage of $25 \%$; when he moved up two weight classes, his win percentage was $67 \%$ with only an average weight deviation of 2.85lbs. It has been noted throughout the wrestling literature $9,16,17,18,19,20,21,22,26$, that RWL has affects on the renal system, thermoregulatory system, cardiovascular system, and has even been known to illicit mood changes and disordered eating during the wrestling season. This particular case is important because not only did his weight loss cause performance changes in win percentages it verified the potential dangerous health issues related to prolonged weight loss and RWL. 
Although several individual wrestlers indicated positive and negative affects during the study, there are three possible explanations why the hypotheses in this study were not substantiated through statistical evidence. These can be related to not taking into account during the study. The athletes' diet, the wrestlers knowledge when weigh ins would take place and the strength of the wrestlers schedule.

First, diet has a very important role in the human body. Without the essential nutrients our body will not have enough energy to sustain us through the activity we demand on a daily basis. Remarkably, wrestlers' often restrict their caloric intake to a point that could be considered disordered eating. For example, in this study, most wrestlers averaged approximately 3270 calories during the off-season but during the in season, the same wrestlers only averaged approximately 2300 calories. One subject even reported he went as low as approximately 850 calories per day during the in season compared with 4000 calories in the off-season. This severe drop in caloric intake could prove to be insufficient fuel for the grueling type of physical activity that is demanded in the sport of wrestling. However, a lower metabolic rate may be seen in athletes who compete well below their natural body weight and in those who frequently lose and regain weight. ${ }^{22}$ This allows the athletes' body to adapt to the demands placed on it so that homeostasis is preserved. Or the athlete may be consuming a high carbohydrate intake. For instance a study ${ }^{21}$ performed with wrestlers found that those with good carbohydrate intake $(4.1 \mathrm{~g} / \mathrm{kg})$ did not have any affect on anaerobic performance. In fact, another study ${ }^{24}$ found that if the wrestlers were exposed to high carbohydrate diets the total sprint work performed was higher than those with lower carbohydrate diets. 
Fogelholm's ${ }^{21}$ research has supported the idea of high carbohydrate intake (60$70 \%$ ) in addition to some sort of high sodium concentration drinks or drinks containing glucose and electrolytes to increase fluid retention. The retention of fluid is important because it will decrease the amount of dehydration experienced by the athlete. There are no specific caloric intake recommendations for wrestlers because it is apparent that the objective of their sport is to obtain a certain weight in order to compete. It is unrealistic for a $125 \mathrm{lb}$ weight class wrestler to eat the same calories as a heavyweight because of the different structural size of each individual athlete.

While both of these numbers were still lower than those performed at baseline, the fact remains that one can overcome some if not most decreased level of glycogen if the athlete maintains a high carbohydrate diet. When an increased amount of carbohydrates are consumed by the athlete, the ability to exercise may be explained because of the higher stored muscle glycogen level which helps minimize losses in FFM and resting metabolic rate. ${ }^{24}$ A study by Hickner et al. ${ }^{25}$ confirmed the assumption that reduced muscle glycogen levels are major contributors to reduced performance.

Second, the athletes' were aware and especially conscious of the fact they were required to weigh-in every Monday and Wednesday. A classic example of this is the Hawthorne effect. A Hawthorne effect is when a change occurred because of what the subjects perceive as special treatment or attention. ${ }^{35}$ Simply, it is the anticipation that something should be happening and they are helping make an impact. The subjects were acutely aware that they were required to weigh in on a specific day at a certain time. Although they were not allowed to see the scale during the weigh-in procedure, they often times would be interested in the outcome and ask the recorder for their result. 
Because they were interested in their weight and they knew the purpose of the study, they may have been made more aware of what they weighed and in turn were able to maintain a more normal weight pattern.

Finally, the athletes' strength of schedule was not taken into account during the season. Each athlete was not evaluated on their ability as a wrestler nor was his opponent's ability taken into account when equations were determined. For instance, it is possible that a subject wrestled ranked wrestlers while they were not ranked, or vice versa. This is important because it may account for why there were more wins during a season or why there were more losses. It is not in the scope of this study to account for such differences although the possibility should not be overlooked.

\section{CONCLUSIONS}

This study did not find any statistically significant relationships between average weight deviations and win percentages in either the $1^{\text {st }} 8$ weeks of the regular season or the $2^{\text {nd }} 8$ weeks. Possibly, this is due to the small sample size of the study $(n=13)$. Even though, as a whole, the study did not indicate significant changes, there was an interesting single subject where RWL produced damaging results on mood, renal function, and cardiovascular function; which in turn, affected athletic performance and caused medical complications. Furthermore, the findings in this study may provide further evidence that the new NCAA guidelines for weight certification were a major step in the right direction to maintaining a healthy environment for wrestlers to lose weight. The lack of findings may be significant in the fact that the problem of RWL is being phased out efficiently through the enforcement of NCAA rules. 
Anecdotal evidence also indicated that subjects' felt extreme fatigue during times of RWL although there was no significant relationship between the wrestlers who had a win percentage $>50 \%$ or $\leq 50 \%$ win percentage. Reasons for these outcomes could be because of the diets of the athletes', the knowledge that they were being evaluated on their weight and therefore were able to maintain a more consistent weight throughout the regular season, or because the strength of schedule and opponent was not factored into the study. 


\section{REFERENCES}

1. Kiningham RB, Gorenflow DW. Weight loss methods of high school wrestling. Med Sci Sports Exerc. 2001;33(5):810-813.

2. Brownell K, Steen S, Wilmore J. Weight regulation practices in athletes: analysis of metabolic and health effects. Med Sci Sports Exerc. 1987;19(6):546-556.

3. Opplinger R, Landrey G, Foster S, Lambrecht A. Bulemic behaviors among interscholastic wrestlers: a statewide survey. Pediatrics. 1993:91(4):826-831.

4. American College of Sports Medicine. Position statement on weight loss in wrestlers. Med Sci Sports Exerc. 1976;8:xi-xiii.

5. Dale K, Landers D. Weight control in wrestling: eating disorders or disordered eating? Med Sci Sports Exerc. 1999;31:1382-1389.

6. Houston M, Marrin D, Green H, Thomson J. The effect of rapid weight loss on physiological functions in wrestlers. Phys Sports Med. 1981;9(11):73-78.

7. Kelly JM, Gorney BA, Kalm KK. The effects of a collegiate wrestling season on body composition, cardiovascular fitness and muscular strength and endurance. Med Sci Sports. 1978;10(2):119-124.

8. Kenney HE. The problem of weight making for wrestling meets. J Health Phys Educ. 1930;1:24-25,49.

9. Steen S, Brownell K. Patterns of weight loss and regain in wrestlers: has the pattern changed? Med Sci Sports Exerc. 1990;22(6):762-768.

10. Center for Disease Control. Hyperthermia and dehydration related deaths associated with intentional rapid weight loss in three collegiate wrestlers- North Carolina, Wisconsin, and Michigan. Nov-Dec 1997. J Am Med Assoc. 1998;279(11):824-825.

11. Utter A. The new national collegiate athletic association wrestling weight certification program and sport seasonal changes in body composition of collegiate wrestlers. J Strength Cond Res. 2001;15(3):296-301.

12. National Collegiate Athletic Association. NCAA wrestling committee recommends rule changes (memorandum). April 13, 1998.

13. National Collegiate Athletic Association. NCAA guideline 2c prevention of heat illness. www.ncaa.org/library/sports sciences/sports med handbook/2003- 04/2c.pdf. 
14. National Athletic Trainer's Association News. July 14, 2002. Heat illness position statement. http://www.nata.org/newsrelease/archives/2002 06.html.

15. Imai T, Seki S, Dobashi H, Ohkawa T, Habu Y, Hiraide H. Effect of weight loss on T-cell receptor-mediated T-cell function in elite athletes. Med Sci Sports Exerc. 2002;34(2):245-250.

16. Lakin JA, Steen SN, Oppliger PA. Eating behaviors, weight loss methods and nutrition practices among high school wrestlers. J Comm Health Nurs. 1990;7:223234.

17. Landers D, Arent S, Lutz R. Affect and cognitive performance in high school wrestlers undergoing rapid weight loss. J Sport Exerc Psych. 2001;23:307-316.

18. Casa D. Exercise in the heat. 1. fundamentals of thermal physiology, performance implications, and dehydration. J Athl Train. 1999;34(3):246-252.

19. Casa D, Armstrong L, Hillman S, Mountain S, Reiff R, Rich B, Roberts W, Stone J. National Athletic Trainers' Association position statement: fluid replacement for athletes. J Athl Train. 2000;35(2):212-224.

20. Choma C, Sforzo G, Keller B. Impact of rapid weight loss on cognitive function in collegiate wrestlers. Med Sci Sports Exerc. 1998;30(15):746-749

21. Fogelholm M. Weight reduction and sport performance. Sports Med. 1994;18:240267.

22. Steen S, Oppliger R, Brownell K. Metabolic effects of repeated weight loss and regain in adolescent wrestlers. $J$ Am Med Assoc. 1988;26(1):47-50.

23. Serfass Rc, Stull GA, Alexander JF. The effect of rapid weight loss and attempted rehydration on strength and endurance of the handgripping muscles in college wrestlers. Res Q Exer Sport. 1984;55:46-52.

24. Horswill CA, Hickner RC, Scott JR, Costill DL, Gould D. Weight loss, dietary carbohydrate modifications, and high intensity physical performance. Med Sci Sports Exerc. 1990;22(4):470-476.

25. Hickner RC, Horswill CA, Welker JM, Scott J, Roemmich JN, Costill DL. Test development for the study of physical performance in wrestlers following weight loss.

26. Klinzing JE, Karpowicz W. The effects of rapid weight loss and rehydration on a wrestling performance test. J sports Med. 1986;26(2);149-156.

27. Armstrong LE, Costill DD, Fink WJ. Influence of diuretic-induced dehydration on competitive running performance. Med Sci Sports Exerc. 1985;17:456-61. 
28. Utter A, Stone M, O’Bryant H, Summinski R, Ward B. Sport-seasonal changes in body composition, strength, and power of college wrestlers. J Strength Cond Res. 1998;12(4):266-271.

29. Schmidt WD, Corrigan DL, Melby CL. Effect of chronic aand acute dehydration on high power exercise performance. Med Sci Sports Exerc Supp. 1990;22:S89

30. Kraemer WJ, Fry AC, Rubin MR, Triplett-McBride T, Gordon S, Koziris P, Lynch J, Volek J, Meuffels D, Newton R, Fleck S. Physiological and performance responses to tournament wrestling. Med Sci Sports Exerc. 2001;33(8):1367-1378.

31. Scott J, Horswill C, Dick R. Acute weight gain in collegiate wrestlers following a tournament weight-in. Med Sci Sports Exerc. 1994;26:1181-1185. Int J Sports Med. 1991;12:557-562.

32. Bergstrom J, Hultman E. A study of glycogen metabolism during exercise in man. Scand J Clin Lab Invest. 1967;19:218-228.

33. BerstromJ, Hermansen L, Hultman E, Saltin B. Diet, muscle glycogen, and physical performance. Acta Physiol Scand. 1967;71:140-150.

34. Song T, Cipriano N. Effects of seasonal training on physical and physiological function on elite varsity wrestlers. J Sports Med. 1984;24:123-130.

35. Shivers C. Halos, horns, and hawthorne; potential flaws in the evaluation process. Profess Safety. 1998;43(3): 
APPENDICES 


\section{APPENDIX A}

\section{THE PROBLEM}

\section{Research Question}

Wrestling is a very competitive sport in Division I, II, and III colleges and universities around the country. Historically it is believed that to have a competitive edge it is necessary to wrestle at the lowest weight possible. ${ }^{1}$ Due to this belief, countless adolescents and young adult males are using weight loss techniques that are detrimental to the health and well-being of these athletes. ${ }^{1}$ In addition to the weight-loss techniques, athletes loose sometimes more than 10 pounds 5 days prior to a wrestling match. ${ }^{1}$ These unhealthy practices was exemplified when three Division I collegiate athletes lost their lives in $1997 .{ }^{10}$ After this incident, the NCAA made rule changes that help the athlete, coaches, and the athletic training staff control the amount of weight lost during the preseason and season. ${ }^{11,12}$ The fact remains, unfortunately, that some athletes will continue to use possible life-threatening weight loss techniques that continually cycle their weight throughout the wrestling season. There are two questions presented 1) does weight fluctuate between two different time points from the competitive wrestling weight and 2) is there a difference between the wrestlers that lose the least amount of weight during the season and those that lose the most amount of weight during the season? Experimental Hypothesis

1. The wrestlers will have better weight management in the second time period than in the first time period and this will correlate with win percentage.

2. The wrestlers than have a win percentage $>50 \%$ will have a lower average weight deviation than those with a win percentage $\leq 50 \%$. 
Assumptions

1. All subjects will complete the surveys with complete honesty and to the best of their ability.

2. All scales used to weigh-in subjects will be certified by the standards required by the rules and regulations of the NCAA Wrestling Federation.

3. The subjects will weigh-in according to the protocol set by the examiner.

4. All weights recorded will be confidential and seen only by the examiner and recording assistant. When the results are recorded they will be coded to ensure subject anonymity.

Delimitations

1. My results are not generalizable to the rest of the United States because the study only includes Division I athletes of the West Virginia University wrestling team.

Operational Definitions

1. Bulimia Nervosa - a psychological eating disorder that is defined binge eating with a sense of loss of control. 5

2. Dehydration - the act of removing water from the body.

3. Diuretics - a method of weight loss that increases the body's production of urine and can lead to dehydration.

4. Disordered eating - a patterned transient behavior that is present due to the demands of the sport and the fear of not being able to compete due to weight restriction. This usually resolves after the season and does not become an eating disorder. ${ }^{5}$

5. Eating disorder - a clinically diagnosable syndrome that involves individuals who "exhibit severe emotional distress and/or specific psychopathologies that go beyond concerns about weight and the use of weight reduction methods." 5

6. Electrolytes -an ionized salt in blood, tissue fluids, and cells that include sodium, potassium, and cholorine. ${ }^{36}$

7. Hydration status - the status of the wrestler's hydration level, measured by a refractometer and should be below 1.02 . 
8. Hydrostatic weighing - a method to determine body density. The subject is placed underwater and then asked to expel the maximum amount of air from their lungs possible. The subject is then weighed and percent body fat can then be calculated. ${ }^{37}$

9. Lowest allowable weight (LAW) - the minimum body weight the NCAA allows a wrestle to wrestle at under the rule changes in 1998. This is performed twice during the season. This is represented at $5 \%$ body fat in the athletes. 38

10. Minimum wrestling weight - "determines the permanent certified weight class for each wrestler for the competition year." 38

11. Rapid weight loss (RWL) - weight loss that is frequent, rapid, and large, many times wrestlers have a change of body weight between $2-12 \%$ in $2-48$ hours before a match. ${ }^{2}$

12. Refractometer - a scientific device used to test the specific gravity of urine.

13. Rehydration - adding water to the body after a period of dehydration.

14. Shadow wrestling - the act of the wrestler moving with an imaginary wrestler for practice.

15. Specific gravity of urine - used to establish (LAW 1). It is determined by a hand-held refractometer. If the specific gravity is above 1.02, the athlete is considered dehydrated. ${ }^{38}$

16. Weight cycling - the method of losing weight (5\% of more for collegiate athletes, $7 \%$ or more for high school athletes) before a match in order to compete at a lower weight class ${ }^{39}$ and after the match gaining the amount back, thereby, consistently being above their wrestling weight class.

\section{Limitations}

1. Existing threats to internal validity in this project included testing, history, maturation and mortality. It is possible that events occurred throughout the course of this project that may influenced the opinions of the panel on the proposed components. Thus, the components were invalid based on history alone. Also, maturational or psychological changes that occurred external to the project, influenced the response of the panel and could have skewed the results. The choice of testing is also a conceivable threat to internal validity, especially when referring to the participant's response on a rating scale. Finally, mortality is the most important threat to the study due to injured athletes and changed line-ups. 
2. Threats to external validity included the selection of the participants and generalization of our findings to other settings. This generalization of our findings to other settings again demonstrates the chance of a possible threat to external validity. The target population of this project was wrestlers at the University. The study did not include any wrestlers from any other universities, colleges, or Division II or III athletes.

Significance of the study

The practical significance of this study is to monitor the athletes' weight loss throughout the regular season to see if the athletes' weight is relatively consistent. Through these weight measurements, we can determine if there is a relationship between the amount of weight lost leading up to a match and their win/loss record. By showing that a weight maintenance program will help increase the chance of success on the wrestling mat, we hope to eliminate harmful means of weight loss. Additionally, we hope to educate the athletes that use more weight cycling methods preceding a match that the method of weight-loss used is less effective and in fact harmful to their health.

Other advantages of this study are to provide education to the coaching staff and the sports medicine staff on the importance of healthy weight loss habits. Wrestling is notorious for the weight cycling that may increase the risk for disordered eating ${ }^{1}$ that occurs during the season. This study will show that a regimented eating lifestyle will increase the chances to perform better during competition. 


\section{APPENDIX B \\ LITERATURE REVIEW}

Introduction

The sport of wrestling has been the focus of recent research due to the tragic deaths of three collegiate wrestlers in 1997. Many harmful weight loss techniques have been identified and subsequently prohibited by the NCAA because of the awareness of the potential pathological affects associated with these types of practices. In addition to physiological pathologies that may occur during rapid weight loss, the medical community has identified possible cognitive and mood disturbances. Furthermore, there is a concern that the eating habits of wrestlers may coincide with that of eating disorders and disordered eating.

The medical community has written multiple statements that include both the detrimental affects of rapid weight loss and recommendations to help control this practice within the wrestling community. The recommendations put forth in these position statements seem to mirror those that have been made since the 1970's and earlier. It is clear that the concern for the wrestlers has manifested into better weight loss rules in the sport of wrestling, however; it is unclear how many athletes adhere to these recommendations.

This paper will examine the prevalence of weight loss techniques utilized by the athletes during the season. Furthermore, we will examine the affects of weight loss on cognition, mood, and eating patterns. Finally, this paper will review literature written on the affects of rapid weight loss on the cardiovascular system, the affect of dehydration on 
the cardiovascular system, aerobic performance, anaerobic performance, and the success rate of athletes during rapid weight loss.

Weight Loss in Wrestling

Although wrestling participation has decreased since the 1970s, a survey performed by the National Federation of State High School Associations (NFSHSA) indicated wrestling to have the sixth highest male participants from 1998-1999. ${ }^{40}$ This relatively recent surge of enthusiasm for the sport has also increased awareness of the potential harmful effects of the sport. There is strong concern involving the athletes' means of "making weight." 7 This has been taken to such extreme measures of weight loss that it was a contributing factors for tragic deaths a few years ago. ${ }^{30}$ Many times, athletes will attempt to lose 10-12 pounds of body weight 3-4 days before a match in

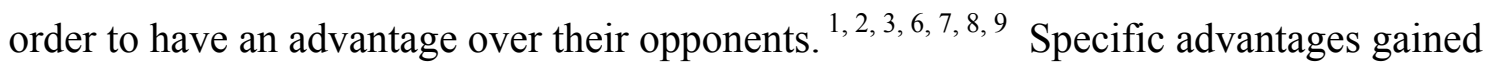
through the practice of competing at a lower weight class are thought to be strength, speed increases, and leverage increases when competing at a weight class well below their natural weight. ${ }^{1,2,3}$ However, Roemmich and Sinning ${ }^{41}$ reported a reduction in muscular strength and loss of lean tissue. It should be noted, that a great many other factors effect wrestling performance. In fact, a preliminary investigation states "it is not known whether acute weight gain or a weight advantage is related to success," and there was no indication a relationship is present. ${ }^{31}$

Previous research has indicated the average wrestler may cut weight approximately 15 times each season ${ }^{2,3}$ Additionally, Brownell et al. ${ }^{2}$ reported an average of $41 \%$ of athletes report a weight variation of 5.0-9.1 kg every week of the season. Oppliger et al. ${ }^{3}$ reported studies that noted a range of $3.1-4.5 \mathrm{~kg}$ of weight loss 
weekly. Other studies delve more deeply into weight loss practices. A study performed by Kiningham et al. ${ }^{1}$ stated that a survey given to 2532 wrestlers revealed $62 \%$ of the wrestlers lost more than 5 pounds 5 days before the match and 16\% lost more than 10 pounds before a match. The average weight a wrestler lost 5 days before the match was 6 pounds. ${ }^{1}$

Wrestlers can achieve weight loss through a variety of methods. These methods often include and are not limited to excessive exercise, caloric restriction, reduction of water intake, thermal dehydration, saunas, rubber or plastic workout suits, heated wrestling rooms, vomiting, laxative, diet pills, and diuretic use. 1,3, 6,9, 16, 42 Frequency of weight loss methods have been investigated with 1 in 4 wrestlers curbing their eating habits 3-4 times per week. ${ }^{1}$ Furthermore, $2 \%$ of wrestlers used diet pills, diuretics, and/or laxatives at least weekly as a method of cutting weight and another $2 \%$ reported the use of vomiting to lose weight. ${ }^{1}$ Another study performed by Lakin et al. ${ }^{16}$ examined weight loss methods of wrestlers. The primary method of weight loss was increased exercise (approximately 84\%), 75\% restricted food, $41 \%$ fluid, and $66 \%$ used gradual dieting. ${ }^{16}$ In addition to these more common methods of weight loss, diet pills were used by $6 \%$ of the wrestlers and a smaller amount of wrestlers vomiting, using laxatives, and diuretics were also practiced by the athletes. ${ }^{16}$ These potentially harmful weight loss practices are widespread throughout the sport of wrestling and are not just confined to an elite group of wrestlers. ${ }^{1}$

\section{Eating Disorders}

Some researchers ${ }^{3,5,16}$ point out that methods such as self-induced vomiting, laxative and diuretic misuse, excessive exercise, and fasting that are used to aid the 
wrestler in making weight are symptomatic of bulimia. These unhealthy weight loss practices have given rise to the question of eating disorder risks in wrestling. A report by Dale and Landers ${ }^{5}$ states that of 25 wrestlers using the Eating Disorder Inventory (EDI), $16 \%$ had pathological profiles of an eating disorder. It is important to understand however that while wrestlers may exhibit indications of an eating disorder, bulimia is a psychological disorder that will have emotional distress as well as sense of loss of control. Moreover, Dale and Landers ${ }^{5}$ report that the eating patterns shown by wrestlers throughout the season is only transient and is therefore not true bulimia. This trend has been also reported in studies that show food preoccupation is reduced or disappeared after the season. ${ }^{3,21}$ A study from Lathrop et al. ${ }^{43}$ reported that during the season wrestlers exhibited pathological eating behaviors during the season but the behaviors did not continue after the season. These patterns of transient behaviors indicate that wrestlers may be at higher risk for eating disorders, ${ }^{9,}{ }^{43}$ although this statement was not supported in a another study ${ }^{5}$ which stated that participation in wrestling does not ultimately put the athlete at greater risk for developing an eating disorder such as bulimia. In fact, wrestlers were generally not apprehensive about body shape and were generally only worried the day before the match about their weight. Furthermore, it was stated that the wrestlers' exhibit patterns of disordered eating that is contributed to making weight and is not observed in the off season.

\section{Mood Changes}

Rapid weight loss in wrestlers has also been connected with mood disturbances and cognition deficits. Choma et al. ${ }^{20}$ noted that after wrestlers lost approximately $6.2 \%$ of body weight (BW), cognitive tests scored were significantly lower on the digit span 
and story recall tests than their matched control groups. The study did not show any affect on attention, visual acuity, or visuomotor skills. ${ }^{20}$ Results from a follow up study by Landers et al. ${ }^{17}$ reported no evidence to support the Choma et al. ${ }^{20}$ claim for cognitive deficits during rapid weight loss (RWL). This could have been due to the distraction of an upcoming competition. ${ }^{17}$ When Landers et al. ${ }^{17}$ controlled for competition, no differences in digit span performance, or any other cognitive measures were noted. Another potential downfall with Choma et al. ${ }^{20}$ findings of cognitive deficits could be due to cognitive test timing. The tests were conducted post weigh-in when the athletes would usually eat and rehydrate themselves therefore, be further distracted during the test. ${ }^{17}$ Landers et al. ${ }^{17}$ stated that cognitive performance may be influenced by a combined effect of RWL, competition stress, and intense physical training but may not show until RWL reaches dangerous stages.

Mood disturbances have been documented in wrestling during periods of rapid weight loss. ${ }^{17,20,21}$ After periods of RWL, wrestlers exhibit a more negative mood state than the controls. ${ }^{20,21}$ This difference usually returned to baseline after rehydration. ${ }^{20} \mathrm{~A}$ study performed by Horswill et al. ${ }^{24}$ indicated that weight loss decreased positive moods and increased negative moods of confusion, depression, anger, fatigue, and tension. A study by Nagle et al. ${ }^{44}$ stated indicated the more successful wrestler scored lower than less successful wrestlers on depression, tension, confusion, fatigue, and anger, but higher on vigor. Interestingly these negative moods states are replicated when athletes over-train and become stale. ${ }^{24}$ Additionally, Landers et al. ${ }^{17}$ reported that negative mood states correlated with RWL. This supports Choma et al. ${ }^{20}$ claims that mood state changes are indeed influenced by periods of RWL. Steen and Brownell ${ }^{9}$ further examined the mood 
states of wrestlers through a questionnaire given to high school and college athletes. Of the college wrestlers that responded $(n=63), 75 \%$ experienced moderate to severe fatigue, $66 \%$ reported anger, $33 \%$ anxiety, and $23 \%$ had feelings of isolation. Both high school and college athletes reported depression and low self-esteem (24\% and 12\% respectively). ${ }^{9}$

Physiological Effects of Weight Loss

Excessive weight loss in wrestlers can cause severe health problems that may have detrimental effects on the cardiovascular system, thermoregulartory responses, renal function, immunosuppression ${ }^{15}$, and athletic performance. ${ }^{1,9,16,17,18,19,20,21,22,23}$ The Centers for Disease Control (CDC $)^{10}$ reported three case studies where death was the result of rigorous weight loss regimens used by three collegiate athletes. In each case, the athletes were cutting weight in an attempt to qualify for a lower weight class at a wrestling tournament.

Dehydration and Cardiovascular response to exercise: During exercise, the cardiovascular system has multiple responsibilities. It is directly responsible for delivering blood to the rest of the body and the muscles that are operational. "The circulatory response during exercises involves 3 components including skin and muscle vasodilation, nonactive tissue vasoconstriction, and maintenance of blood pressure."18 Blood is increased to the areas where work is being performed and diminished to areas where the demand is not as great. When intense exercise and heat are combined the cardiovascular system $(\mathrm{CV})$ is unable to meet the demands of the skin and muscles together. Blood pressure maintenance supercedes the need to maintain "skin blood flow (i.e., body cooling) and muscle blood flow (i.e., performance capacity)."18 The inability 
of the skin to reduce body temperature through evaporation can lead to hyperthermia. These metabolic alterations can be seen in an increased lactate level, muscle vasoconstriction and increased muscle temperature. ${ }^{18}$ (Figure 1)

Dehydration causes thermoregulatory changes and CV changes in addition to others during exercise. When coupled with intense exercise, dehydration ${ }^{17,19,21,24,25}$ will decrease performance capacity due to the heart rate being unable to compensate for the larger decreases in stroke volume. ${ }^{18}$ It has also been reported that the magnitude of CV changes are proportional to water deficit. ${ }^{19,21}$ The filling pressure of the heart decreases due to increased viscosity and decreased blood volume thereby decreasing filling pressure and stroke volume. ${ }^{18}$ This is important for the athlete to realize because their overall performance capacity will decrease due to the increased temperature. They will not be able to maintain the exercise for as long of a time when compared to those athletes that are cooled and adequately hydrated.

Individuals who exercise while dehydrated may experience a lower heat tolerance especially when dehydrated $8 \%$ or more. ${ }^{18}$ However, it has also been reported that when dehydration levels of $1-2 \%$ are reached, physiological function such as temperature control could decrease and at a dehydration level of $3 \%$ or higher the risk of developing heat exertional illnesses increase. ${ }^{19}$ When an athlete is dehydrated, the osmolarity of the body changes and the distribution of fluids change. ${ }^{18}$ The "changes in distribution of body fluids are associated with the ability to mobilize fluids from the intracellular space, which is intimately linked with sweat sodium concentrations." Therefore, the sweat sodium concentrations after acclimatization may help keep plasma volumes at a steady level during dehydration. 
Figure 1. Effects of exercising in the heat ${ }^{18}$

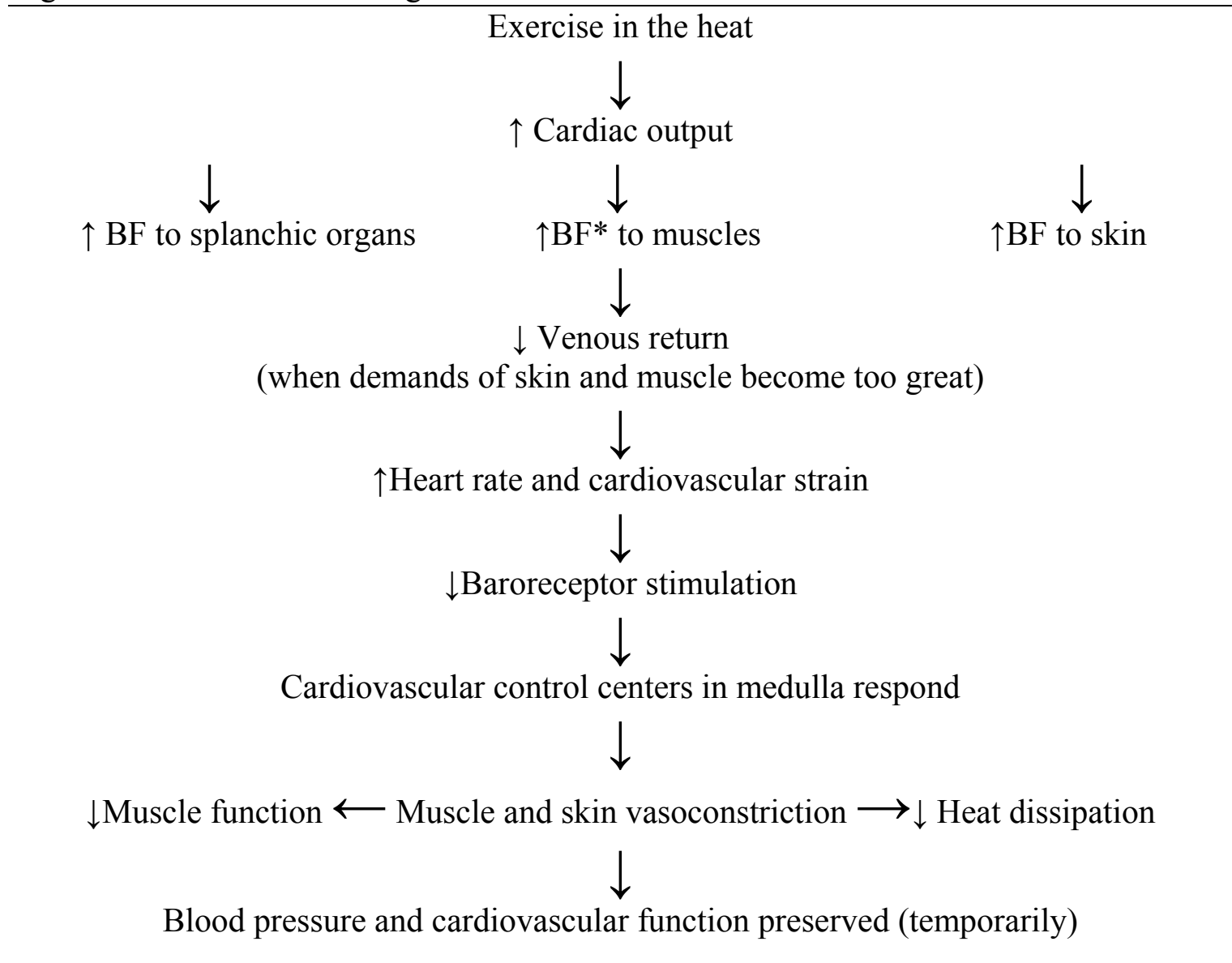

*BF $=$ Blood Flow

Usually, sweat is hypotonic to body fluids and if athletes are not adapted to the heat, there would be a high concentration of electrolytes in their sweat. ${ }^{45}$ As the athlete becomes mildly dehydrated, extracellular fluid is mostly lost, however when the amount of dehydration increases fluid from the intracellular area is lost. ${ }^{18}$ The fluid redistribution ultimately "stimulates volume and fluid receptors in the body to conserve fluid and stimulate rehydration."

Dehydration can have numerous pathological effects on muscle tissue which may be attributed to a reduction in plasma volumes that limits oxygen transportation to the muscles. ${ }^{21}$ This limitation in oxygen transportation may not allow the athlete to exercise 
at the desired intensity for the amount of time needed to successfully complete the workout or competition. The physiological effects include an "increased rate of glycogen synthesis, compromised buffering capacity of the muscle tissue, elevated muscle temperature, and decreased substrate exchange." ${ }^{18}$ These metabolic changes have produced somewhat conflicting results. Studies ${ }^{18,23}$ have revealed muscular endurance deficits in accordance with dehydration but these deficits occur within a window. Decreases in strength performance are usually associated with a $5 \%$ or more reduction in body weight. ${ }^{7,18,24,28,30,46}$ Rehydration usually does not occur within the time limit between weigh-in and match time. ${ }^{1,6,7,21,24,46}$

Physiological responses and performance: Fogelholm ${ }^{21}$ reported on the effects of weight reduction on sport performance. Studies ${ }^{21,25}$ have found that aerobic performance declined after dehydration with diet and exercise, or other weight loss techniques. Interestingly when diuretics were used, aerobic performance declined more noticeably than weight loss with diet and exercise. ${ }^{21}$ There is slight controversy with maximal oxygen uptake $\left(\mathrm{VO}_{2} \max \right)$ due to conflicting results from experimental studies. Some studies ${ }^{47,48}$ report that there is a reduction while Houston et al. ${ }^{6}$ reported no significant change in $\mathrm{VO}_{2}$ max levels after rapid weight loss. Song and Cipriano ${ }^{34}$ noted an increased $\mathrm{VO}_{2}$ max after seasonal training of wrestlers. This is important to endurance athletes because the higher the $\mathrm{VO}_{2}$ max the better the exchange of oxygen to the functioning muscles. However, the values reported by $\mathrm{Yoon}^{49}$ indicated the $\mathrm{VO}_{2}$ max measures are not as high when compared with endurance runners, but still higher than the average active male. The increase may be due to the increased efficiency of the respiration muscles in conjunction with the aerobic training of the athletes. ${ }^{34}$ 
Currently, anaerobic performance has been shown to both decrease and remain the same during rapid weight loss. ${ }^{21,25}$ Short periods often used by wrestlers to rehydrate before matches are not affective in returning anaerobic performance to baseline before competition. ${ }^{21,26,30}$ However, when exercise is prolonged to 5-24 hours after hydration and caloric intake, anaerobic performance is unchanged. ${ }^{21,26} \mathrm{~A}$ possible explanation for the changes may be due to the diet of the athlete. In wrestlers with good carbohydrate intake $(4.1 \mathrm{~g} / \mathrm{kg})$ anaerobic performance was not affected. ${ }^{21}$ A study performed by Horswill et al. ${ }^{24}$ reported that when wrestlers are exposed to high carbohydrate diets the total sprint work performed was higher than the lower carbohydrate diets however both results were decreased from baseline measurements. In a case study ${ }^{50}$ performed on an elite wrestler before the Olympic trials, showed despite a decrease in caloric intake, the diet consisted of increased carbohydrates which allowed for "continued training by theoretically maintaining muscle glycogen stores and minimizing losses in both fat-free mass and resting metabolic rate." Fogelholm ${ }^{21}$ also reported the role of carbohydrate intake and performance. Low carbohydrate intake is unable to sustain intense training loads which may be due to reduced glycogen stores. ${ }^{21}$ Glycogen levels can sometimes cause glycogen depletion to be $29 \%$ after the first 48 hours with an additional $25 \%$

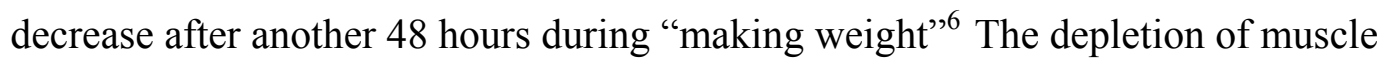
glycogen stores is thought to contribute to fatigue and therefore, decrease in performance. ${ }^{24}$ This concurs with Hickner et al. ${ }^{25}$ study that dehydration and reduced glycogen stores in exercising muscles are major contributors to reduced performance. Kraemer et al. ${ }^{30}$ noted that glucose levels were significantly elevated after the match when compared with baseline measures. It should be noted, that as in previous studies, 
the contribution of diet, duration of exercise, and intensity of exercise, are important to determine in the athletes/subjects before performing the study. ${ }^{25}$

Effect on strength: Previous research ${ }^{25,26}$ has shown a significant decrease in upper body power after weight loss. Wrestlers reportedly lost approximately $4.5 \%$ body weight which is equal to or maybe less than what is normally lost throughout the collegiate wrestling season which may cause a decrease in performance during the match. ${ }^{25}$ Hickner et al. ${ }^{25}$ study is somewhat unique in that it tested only upper body strength using a modified Wingate test, which makes it specific to wrestling. The modified Wingate test required the subjects to achieve maximum effort and maintain this for 30 seconds of arm cranking of an isokinetic ergometer. Studies using the Wingate tests have yielded conflicting results which questions the reliability of that test. A study performed by Webster et al. ${ }^{28}$ reported that weight loss procedures followed by collegiate athletes decreased performance in areas such as aerobic and anaerobic capacities, upper body strength, and aerobic power. Schmidt et al. ${ }^{29}$ found that both acute and chronic dehydration yielded a decrease in high power exercise performance. Roemmich and Sinning ${ }^{41}$ noted there were significant decreases from preseason measures to late season measure on knee extension power. Houston et al. ${ }^{6}$ however, failed to find any significant decrease in performance during an anaerobic run during the weight loss time. Another study $^{7}$ revealed there were only a few significant differences in muscular strength and endurance which may be due to the athletes' high level of physical fitness.

Weight cycling and performance: Steen et al. ${ }^{22}$ examined the effect of weight cycling and metabolic weight. Tests from indirect calorimetry and anthropometry revealed significant differences between weight cyclers vs. non weight cyclers. The 
resting metabolic rate for cyclers was $154.6 \mathrm{vs} 177.2 \mathrm{~kJ} / \mathrm{m}^{2} / \mathrm{h}$ for non weight cyclers. Additionally, oxygen consumption was significantly lower for cyclers than non-cyclers. ${ }^{22}$ The lower metabolic rate may be seen especially in those athletes that compete furthest below their natural body weight and in those who frequently lose and regain weight throughout the season.$^{22}$ Furthermore, the lowered metabolic rate may affect body weight regulation. A theory that may explain the decreased lower metabolic rate is a higher fat content in the weight cyclers than non-cyclers. However, this has not been substantiated because current research ${ }^{22,47}$ has not shown similarities between the two groups. Other effects of a lowered metabolic weight may be health risks and psychological implications due to the frustration of dieting which may have long-term affects. ${ }^{22}$

Muscle strength was observed during a study in which the wrestlers were asked to perform a back and leg lift. ${ }^{51}$ A questionnaire was first distributed to determine that it was necessary to lose weight before a competition, however, the wrestlers felt this lead to decrease in athletic performance. During testing the results showed a muscular strength on the third try than the first in both the back and leg lift. The improvement may be related to a warming up effect instead of a learning effect. A study performed by Bosco et al. ${ }^{52}$ found no significant differences in isometric strength during knee extension, dominant and non-dominant hand grips, leg extension, back extension, total strength, and ratio of total strength divided by body weight after a regiment hypohydration and a prescribed diet. Additionally, Houston et al. ${ }^{6}$ reported no significant decrease in performance time on run to exhaustion on the treadmill during weight loss. A decrease in muscle torque was apparent especially for low-speed contractions in large muscles. Armstrong et al. ${ }^{27}$ stated there was a decrease in performance in aerobic running events 
and there was a significant decrease in anaerobic capacity during rapid weight loss. Webster et al. ${ }^{28}$ indicated a small but significant decrease in peak torque and average work in the chest and shoulder but not in the knee in their study. Moreover, rapid weight loss may have a stronger affect on upper body strength compared with lower body strength. This is extremely important for wrestlers to realize because they need a vast amount of strength in their upper body during competition.

Recommendations for the Wrestling Community

Position statements have been written by the American College of Sports Medicine (ACSM) $)^{4,53}$ and the National Athletic Trainers' Association (NATA) ${ }^{19}$ regarding the health risks and rule change recommendations for the sport of wrestling. The ACSM initially wrote a position statement on weight loss in wrestling in 1976. The position statement outlines the standard practice of wrestlers losing 3-20\% weight loss at preseason before competition. ${ }^{4}$ Furthermore, combinations of fluid and caloric restriction causes reduction in muscular strength, work performance, plasma and blood volumes, cardiac functioning, smaller stroke volumes, lower oxygen consumption, thermoregulatory processes, renal blood flow and volume of fluid filtered by the kidney, depletion of liver glycogen stores, and an increase in the amount of electrolytes lost. ${ }^{4}$ Due to these very detrimental effects, the $\mathrm{ACSM}^{4}$ recommended assessing body composition of each wrestler weeks in advance to the regular season and emphasizing the importance of a proper diet. Also, the ACSM discouraged the practice of dehydration and recommended the prohibition of saunas, rubber suits, steam rooms, laxatives, and diuretics to make weight. 
The ACSM then revised the position statement of 1976 in 1996 due to the increased information and research investigating the harmful effects of rapid weight loss in wrestling. ${ }^{53}$ Additional harmful effects of cutting weight include altered hormonal status, decreased protein nutritional status, impedance of growth and development, psychological states, impairment of academic performance, and possibly pulmonary emboli, pancreatitis, and reduced immune function. ${ }^{53}$ The detrimental effects of weight cutting can be read in greater detail in Table 1. Recommendations were then added to the ACSM position statement to educate, discourage use of laxatives, saunas, diuretics, and rubber suits, schedule daily weight ins, adopt new laws by wrestling governing bodies, and emphasize adequate daily caloric intake. ${ }^{53}$

The NATA ${ }^{19}$ also published a position statement on fluid replacement in athletes. Again, a 1-2\% drop in hydration causes compromise of physiological function and dehydration of greater than 3\% further places the athlete at risk for heat illnesses during exercise. Thus, the NATA ${ }^{19}$ recommends establishing a hydration protocol for athletes to consider the athlete's sweat rate, environmental factors, intensity, and duration of exercise. Fluid replacement should equal sweat and urine losses which is usually approximately 7-10 fl oz every 10-20 min. ${ }^{19}$ Hydration rate for wrestling should be checked before weigh-ins or body composition tests to ensure proper hydration. The athletic trainer or health profession should also be aware of the signs and symptoms that can occur with dehydration. The basic signs and symptoms are thirst, irritability, general discomfort, headache, weakness, dizziness, cramps, chills, vomiting, nausea, and heat sensations in the head or neck region, and decreased athletic performance. ${ }^{19}$ 
Table B1. Effects of weight cutting on physiological performance ${ }^{53}$

a,c Little or no increase and possible reduction in muscle strength

a,c Little or no increase and possible decrease in anaerobic power capacity

b,c Lower plasma and blood volume, increased resting and submaximal heart rate, decreased cardiac stroke volume; resulting in decreased ability to sustain work at a constant rate, ie, reduced endurance capacity.

a Lower oxygen consumption

c,d Impaired thermoregulatory processes, which could decrease endurance capacity and increase the risk of heat illnesses during practice

c Decreased renal blood flow and kidney filtration of blood

a,b Depletion of muscle and possibly liver glycogen, which will reduce muscle endurance capacity, the body's ability to maintain blood glucose levels, and accelerate the breakdown the body's protein.

a,c,d Depletion of electrolytes resulting in impaired muscle function, coordination, and possible cardiac arrhythmias

$\mathrm{a}=$ food restriction or fasting, $\mathrm{b}=$ exercise, $\mathrm{c}=$ dehydration, $\mathrm{d}=$ diuretics or laxatives

Rule Changes by the NCAA

In 1997, one year after the ACSM published a new position statement, three deaths occurred in collegiate wrestling ${ }^{10}$ which spurred the NCAA to make rule changes to the sport. These rule changes prohibited the use of "laxatives, emetics, excessive food and fluid restriction, self-induced vomiting, hot rooms, hot boxes, saunas, and steam rooms. ${ }^{12}$ Diuretics are prohibited for all sports sponsored by the NCAA. ${ }^{12}$ Additionally, wrestling room temperatures are not to exceed $75^{\circ} \mathrm{F}$ at the start of practice. ${ }^{12,54}$ Weight assessments were to be performed to determine body composition and specific gravity of urine. The specific gravity of the urine must be $\leq 1.020$ on the refractometer which determines the hydration status of the athlete. ${ }^{55}$ If the athlete is properly hydrated, they may weight-in at that time. If the athlete is not hydrated, they must perform the hydration test no sooner than 24 hours after the failed test. The process is repeated until the athlete passes the hydration status test. Skinfold measurements are then performed by a qualified individual on the athletes' triceps, subscapular, and abdominal areas. The median of each reading is added together to get a sum skin-folds (SUM SF). The body 
density (BD) of the athlete is then calculated from the equation [1.0982 - (SUM SF $x$ $.000815)]+\left[(\mathrm{SUM} \mathrm{SF})^{2} \mathrm{x} .00000084\right]$. Then the percentage body fat is calculated by the equation $[(4.57 / \mathrm{BD})-4.142] \times 100$. Fat weight $(\mathrm{FW})$ is then calculated by body weight (BW) $\mathrm{x}(\% \mathrm{BF} / 100)$, followed by fat free weight (FFW) which is calculated by BW-FW. Through these steps the lowest allowable weight-one (LAW1) is found by FFW/0.95. If the athlete decides to wrestle at a lower weight, they can lose weight according to the procedures for lowest allowable weight-two (LAW2). After the first weigh-in the wrestler can lose no more than $1.5 \%$ body weight per week and the weight could not fall below the minimum wrestling weight determined by the body composition test. $^{12}$

Furthermore, weigh-in times were modified by the NCAA at: one hour before dual meets, tournament weight-ins will be held two hours before the start of the first match on the first day, whereas, all subsequent days the weigh-ins will be held one hour before the first match. ${ }^{12,54}$ Weight classes were changed to $125,133,141,149,157,165$, $174,184,197$, and heavyweight to end at $285 .{ }^{12}$ Finally, all coaches are to be Cardiopulmonary resuscitation (CPR) and first aid certified. ${ }^{12,54}$

The potential harmful effects of rapid weight loss to make the competitive weight class has been followed since 1930 . Kenney ${ }^{8}$ states that it may be necessary to determine the weight class of an individual after training and adequate diet methods. Additionally, Kenney suggested a crude method of developing a lowest allowable weight in 1930 when his article was published. In recent times, other authors have suggested recommendations to ensure the health and safety of wrestlers. A study ${ }^{38}$ performed in 2002 was designed to see if the NCAA's rule changes had any effect on weight loss practices in wrestlers. The 
researchers found that the weight cycling practices of the wrestlers had dropped from 1998-2000. However, they did find that after the summer break they were significantly heavier than their previous seasons wrestling weight. ${ }^{38}$ Utter $^{11}$ also supported an overall "improvement in body composition and had lower seasonal reductions." This may have further implications on the NCAA rules because the wrestlers may have to cut significant amounts of weight in order to certify at the correct lowest allowable weight. ${ }^{38}$ Summary

Wrestling practices and rules have changed dramatically through the years. There is much controversy about the effects weight loss has on athletes. Harmful methods of rapid weight loss such as excessive exercise diuretics, laxatives, vomiting, restricted food and fluid intake, and diet pills have been practiced by the athletes and reported through numerous studies. In addition to the physiological harmful effects of rapid weight loss, mood changes have been observed that include confusion, depression, anger, fatigue, and tension. Cognitive deficits have also been noted during periods of rapid weight loss although this has been contested by other studies that state the cognition deficit could be influenced by other sources not accounted for in the study.

Physiological effects of rapid weight loss can affect the cardiovascular system, thermoregulatory system, renal function, immunosuppression, and performance. Many different factors of weight loss, including dehydration, have a profound affect over these systems in one form or another. Performance decreases have been noted in many studies when athletes have a 1-2\% dehydration level. Also, glycogen levels can be lower during periods of rapid weight loss although there are conflicting reports on this issue.

Strength deficits are noted in the upper body during experimentation which is more 
specific to wrestling than other studies on the lower body. Furthermore, anaerobic and aerobic performance has decreased during periods of dehydration and rapid weight loss which also has strong implications on the sport of wrestling success.

The ACSM, NATA, and NCAA have all stated the damaging physiological effects concerning dehydration in athletics. After the tragedies in 1997, the ACSM rewrote their previous position statement on weight loss in wrestling. It included reported possible harmful effects of rapid weight loss and dehydration such as renal dysfunction, thermoregulatory problems, and cardiovascular problems. The ACSM then added recommendations for rule changes to ensure the safety of the participants in wrestling. The NATA also wrote a position statement on hydration in athletics in which they suggested multiple weigh-ins and fluid replacement rates. The NCAA initiated rule changes such as different weight classes and specific weight certification rules and regulations to help create awareness and promote safety of the wrestling athletes throughout the country. 
APPENDIX C

ADDITIONAL METHODS

Table C1. Informed Consent

\section{CONSENT AND INFORMATION FORM}

Do practice weights vary from wrestling weights throughout the season and is there an effect on win percentage?

\section{Introduction}

I, , have been invited to participate in this research study, which has been explained to me by Rebecca L. Sidener, BS, ATC. She is conducting this research under the supervision of Michelle A. Sandrey, PhD, ATC to fulfill the requirements for a master's thesis in Athletic Training in the School of Physical Education at West Virginia University.

\section{Purposes of the Study}

The purposes of the study are to evaluate 1) to determine if weight fluctuations between two different time points vary from the competition wrestling weight; and 2) to determine if there is a relationship between weight lost throughout the season and win percentages.

\section{Description of Procedures}

This study will be conducted at the West Virginia University wrestling locker room and at Eastern Wrestling League and Division I institutions in Maryland, Ohio, Pennsylvania, Illinois, and Nevada, in competition with the West Virginia wrestling team.

Orientation Procedures

At an orientation meeting, I will be explained the purpose of this study. I will also be given a demographic questionnaire. I understand that if I am chosen for this study, I will be given an informed consent form explaining my rights as a research subject.

If I am an eligible subject, I will be contacted by the principal investigator at on Mondays and Wednesdays of each week during the course of the regular season to weigh in. I understand there are specific weigh-in procedures to be followed as per the National Collegiate Athletic Association (NCAA). I also understand I will weigh in, to the tenth of a pound, on a digital scale that has met NCAA calibration under the 2003 Rules and Regulations Handbook West Virginia University and the institution where dual meets and tournament meets take place. I understand an athletic training student from my institution, a certified athletic trainer from the other institution, or a tournament official will be recording my weight.

$\underline{10 / 21 / 03}$

Page 1 of 2

Version Date

$\overline{\text { Initials }} \overline{\text { Date }}$ 


\section{DO PRACTICE WEIGHTS VARY FROM WRESTLING WEIGHTS THROUGHOUT THE SEASON AND IS THERE AN EFFECT ON WIN PERCENTAGE?}

I understand I will be weighed in according to NCAA rules and regulations, which require me to be nude during the weigh-in. My feet will be placed in the middle of the scale while I face away from the scale reading. I will remain stationary while my arms are at my side. I understand the recorder will be off to my side reading the weight.

I understand the research will start at on November 17, 2003, and the research will end at the finish of the regular season, March 7, 2004. I will then weigh in every Monday and Wednesday after practice. Once my weight has been recorded, I will be allowed to leave. I understand that West Virginia University researchers hope to enroll approximately 20 people in this study. I understand that only 10 subjects' data will be used for both the ANOVA and the t-test equations. I understand the total time for the weigh-in for each subject will take no longer than 5 minutes.

\section{$\underline{\text { Risk and Discomforts }}$}

I understand that I may experience mental discomfort or anxiety; however, I will be facing away from the scale and will not be able to view my weight. I understand there are minimal risks while weighing in. The researcher will maintain a safe, private environment during the weigh-in. I am aware that a male recorder will be present for the weigh-ins. I understand that every precaution has been taken to prevent me from being injured during the weigh-ins. Should any injury occur, I understand Rebecca L. Sidener, BS, ATC will provide first aid and will make any necessary referrals.

\section{$\underline{\text { Alternative }}$}

I understand I do not have to participate in this study.

\section{Benefits}

I understand that this study is not expected to be of direct benefit to me, but the knowledge gained may be of benefit to others.

\section{Contact Persons}

For more information about this research, I can contact Rebecca L. Sidener, BS, ATC at (304) 599-3947 or at rsidener@hotmail.com or her faculty advisor, Michelle A. Sandrey at (304) 293-3295 ext. 5220 or at msandrey@mail.wvu.edu. For more information regarding my rights as a research subject, I may contact the Executive Secretary of the Review Board at (304) 293-7073.

$\underline{10 / 21 / 03}$

$$
\text { Page } 2 \text { of } 3
$$

Version Date

$\overline{\text { Initials }} \quad \overline{\text { Date }}$




\section{DO PRACTICE WEIGHTS VARY FROM WRESTLING WEIGHTS THROUGHOUT THE SEASON AND IS THERE AN EFFECT ON WIN \\ PERCENTAGE?}

\section{Confidentiality}

I understand that may information about me obtained as a result of my participation in this research will be kept as confidential as legally possible. Identifying information on the informed consent form and demographic history questionnaire will be kept confidential by assigning a code number to each informed consent form, demographic history questionnaire, and weight records. I understand that my research records and test results, just like hospital records, may be subpoenaed by court order or may be inspected by the study sponsor or federal regulatory authorities (including FDA if applicable) without my additional consent. I further understand that some of my weigh-in results are necessary to reveal to the NCAA, due to the regulation inherent in my sport. Any weighin records that are necessary to verify my weight during a dual or tournament meet are subject to NCAA rules and regulations. My weigh-in results, obtained during the regular wrestling season, that are not needed during a dual or tournament meet, will remain confidential. In any publications that result from this research, neither my name nor any information from which I might be identified will be published without my consent.

\section{Voluntary Participation}

Participation in this study is voluntary. I understand that I am free to withdraw my consent to participate at any time and that such refusal to participate will not affect my future care, my employee status at West Virginia University, my status or position on the time, or my class standing or grades. Refusal to participate or withdrawal will involve no penalty to me. I have been given the opportunity to ask questions about the research, and I have received answers concerning areas I did not understand. In the event new information becomes available that may affect my willingness to continue to participate in this study, this information will be given to me so I may make an informed decision about my participation team.

Upon signing this form, I will receive a copy.

I willingly consent to participate in this research.

Signature of Subject

Signature of Principal Investigator

$\underline{10 / 21 / 03}$

Version Date

\section{Date}

Date

Page 3 of 3
Time

Time

Initials

Date 
Table C2. Recording Sheet

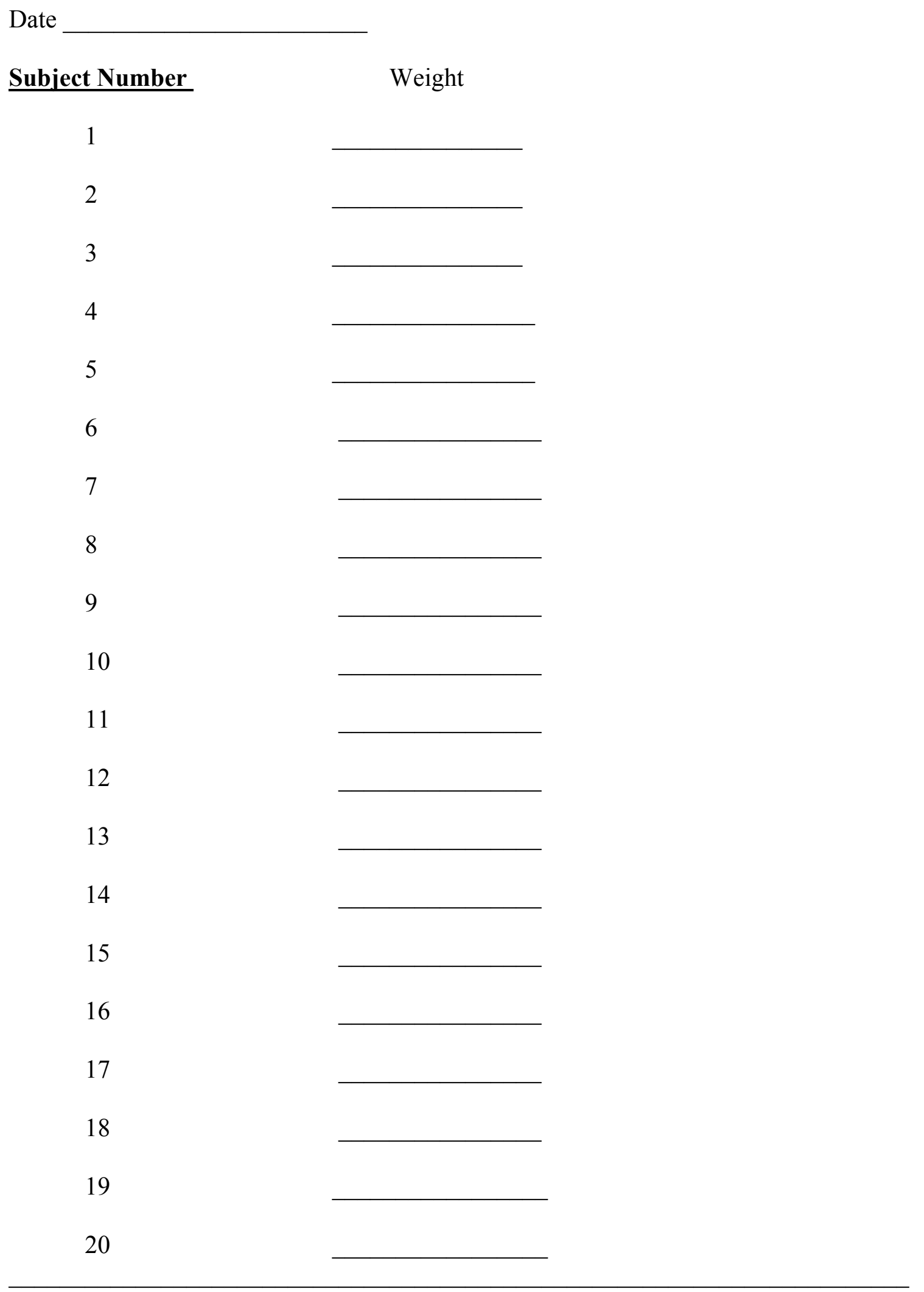


1. During the weigh-in procedure, the recorder will ask the athlete to be nude.

2. The athlete will then step onto the scale placing his back toward the scale reading.

3. The athlete will then be asked to place their feet at the exact middle of the scale while placing their hands at their sides.

4. The athlete will be asked to stand still on the scale.

5. The examiner will be on the left side of the athlete reading the scale output.

6. The weight will be recorded from the digital scale to the tenth of a pound on the data collection sheet.

7. All wrestlers will be identified by a code. 
Table C4. Official weigh-In form

\section{NCAA WRESTLING \\ OFFICIAL \\ Weigh-In Form}

Institution:

Opponent:

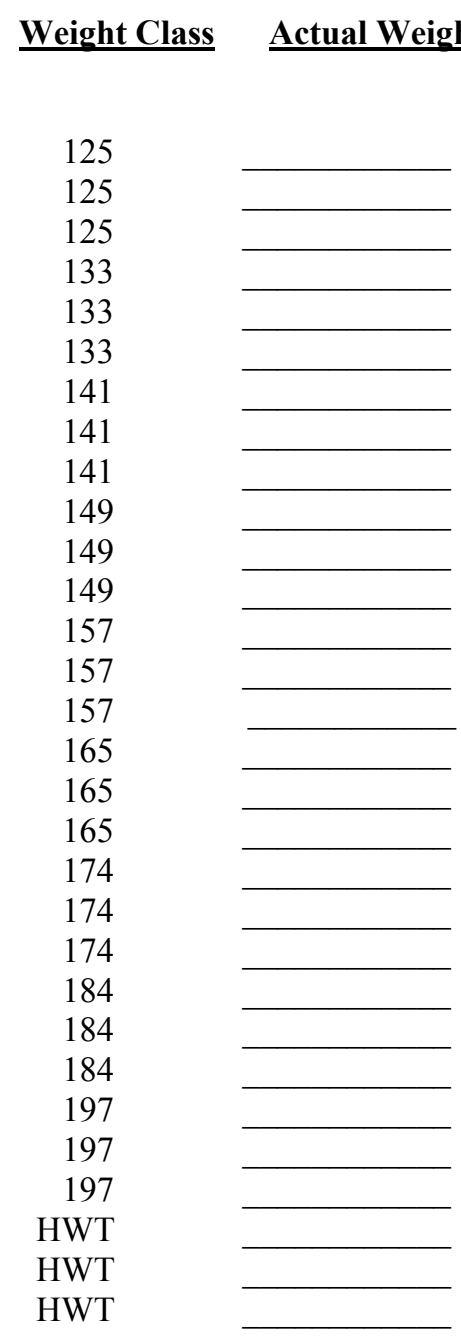

Weigh-In Time Certified by Coach: $\underline{\text { Name and 2002-2003 Certified Weight Class }}$

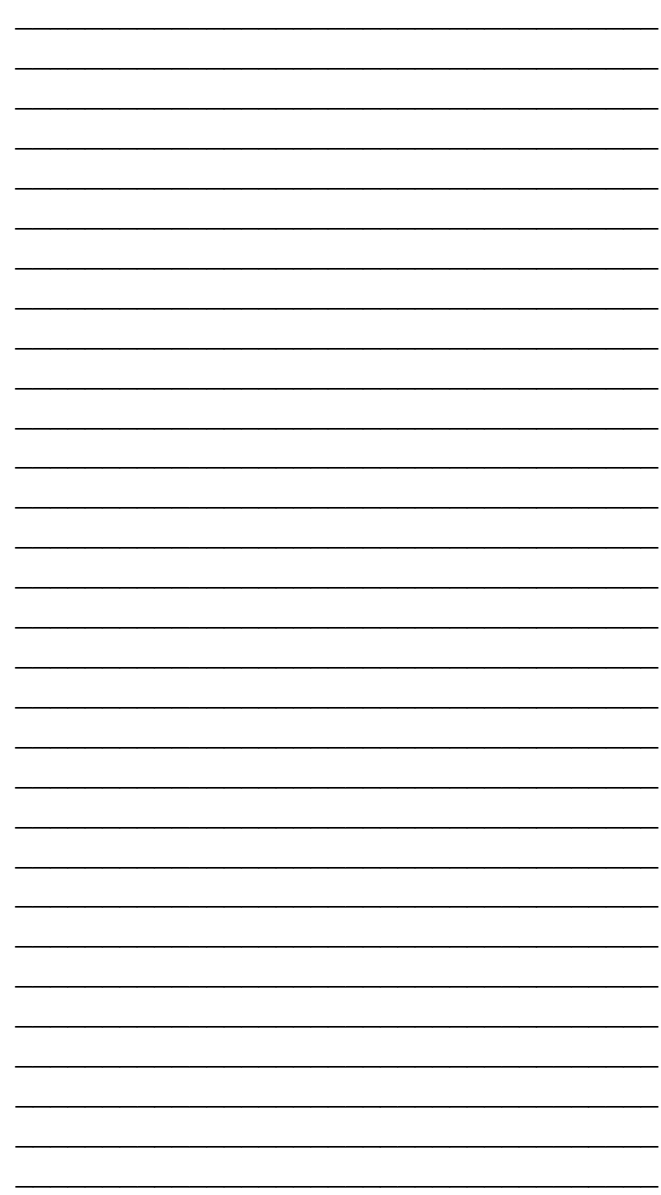

Skin check certified by

Certified by Administrator:*

*if honor weigh-in performed $\underline{\text { Medical/Skin }}$

Check pass/did not pass

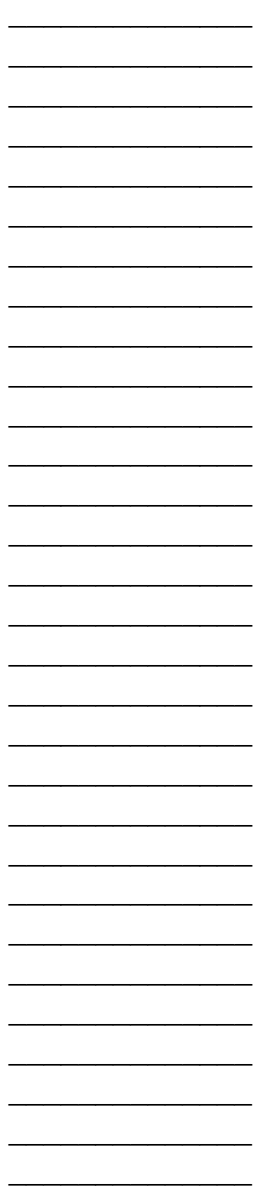

name

***this is a duplicate copy of the NCAA weigh-in form for dual meets and tournaments. 


\section{Table C5. Questionnaire}

1. Age

2. Year in school, circle one FR SO JR SR

3. Number of eligible years left, circle one 12234

4. Wrestling weight certification, circle one

$\begin{array}{llllllllll}125 & 133 & 141 & 149 & 157 & 165 & 174 & 184 & 197 & \text { HWT }\end{array}$

4a. How long have you wrestled in your present weight class?

4b. Has your weight class changed in the past year? Yes No

4c. If you answer to number $4 \mathrm{~b}$ was yes, did you move up or down in weight class?

5. State the total number of years you have been wrestling

6. Please state if you are:

Scholarship Walk-on (please specify full, partial, quarter etc.)

7. What is your average weight during the off season?

8. What is your average weight during the preseason?

9. What is your average weight during the regular season?

10. On average how many calories do you consume in the off season per day?

11. On average how many calories do you consume during the regular season per day?

12. On average how many pounds do you lose 3 days before a match? 2 days? 1 day?

13. How many pounds does your weight fluctuate between matches?

14. How many times do you exercise in the preseason/week?

15. How many times do you exercise during the regular season/week? (Do not include regularly scheduled practice but include any other workouts on your own or lifting activities)

16. How many times do you exercise/week during the off season?

15. What was your win/loss record last season? 


\section{APPENDIX D}

\section{ADDITIONAL RESULTS}

Table D1. Weight Loss Patterns Before Matches

\begin{tabular}{llll}
\hline & Pounds & $\%$ & $\mathrm{~N}$ \\
\hline 3 Days & 8 & $7.7 \%$ & 1 \\
& 7 & $7.7 \%$ & 1 \\
& 6 & $15.4 \%$ & 2 \\
& 5 & $38.5 \%$ & 5 \\
& 3.5 & $7.7 \%$ & 1 \\
& 3 & $7.7 \%$ & 1 \\
& 2 & $7.7 \%$ & 1 \\
& 0 & $7.7 \%$ & 1 \\
\multirow{6}{*}{ Days } & 6 & & \\
& 5 & $7.7 \%$ & 1 \\
& 4 & $23.1 \%$ & 3 \\
& 3 & $15.4 \%$ & 2 \\
& 2 & $30.8 \%$ & 4 \\
& 0 & $15.4 \%$ & 2 \\
& & $7.7 \%$ & 1 \\
& 5 & & \\
& 4 & $7.7 \%$ & 1 \\
& 3 & $23.1 \%$ & 3 \\
& 2.5 & $7.7 \%$ & 1 \\
& 2 & $7.7 \%$ & 1 \\
\hline
\end{tabular}


Table D2. Descriptive Data

\begin{tabular}{|c|c|c|c|c|c|}
\hline Variable & $\mathrm{N}$ & Minimum & Maximum & Mean & St. Deviation \\
\hline Age & 13 & 19 & 23 & 21.08 & 1.04 \\
\hline $\begin{array}{l}\text { Years of } \\
\text { eligibility left }\end{array}$ & 13 & 0 & 3 & 1.38 & .870 \\
\hline $\begin{array}{l}\text { Current wt } \\
\text { certification }\end{array}$ & 13 & 125 & 285 & 163.46 & 43.35 \\
\hline $\begin{array}{l}\text { Years in present } \\
\text { weight class }\end{array}$ & 13 & 1 & 5 & 2.38 & 1.55 \\
\hline $\begin{array}{l}\text { Number of total } \\
\text { years wrestling }\end{array}$ & 13 & 10 & 19 & 14.77 & 2.68 \\
\hline $\begin{array}{l}\text { Calories } \\
\text { consumed during } \\
\text { the off season }\end{array}$ & 13 & 1500 & 4000 & 3269.23 & 780.37 \\
\hline $\begin{array}{l}\text { Calories } \\
\text { consumed during } \\
\text { the regular } \\
\text { season }\end{array}$ & 13 & 850.00 & 3500.00 & 2300.00 & 755.81 \\
\hline $\begin{array}{l}\text { Average pounds } \\
\text { lost } 3 \text { days } \\
\text { before a match }\end{array}$ & 13 & 0.00 & 8.00 & 4.65 & 2.11 \\
\hline $\begin{array}{l}\text { Average pounds } \\
\text { lost } 2 \text { days } \\
\text { before a match }\end{array}$ & 13 & 0.00 & 6 & 3.46 & 1.61 \\
\hline $\begin{array}{l}\text { Average pounds } \\
\text { lost } 1 \text { day before } \\
\text { a match }\end{array}$ & 13 & 0.00 & 5.00 & 2.5 & 1.44 \\
\hline $\begin{array}{l}\text { Number of } \\
\text { pounds of weight } \\
\text { fluctuation } \\
\text { between matches }\end{array}$ & 13 & 2.00 & 10.00 & 6.81 & 2.82 \\
\hline $\begin{array}{l}\text { Average amount } \\
\text { of exercise } \\
\text { during the } \\
\text { regular season on } \\
\text { own (in days) }\end{array}$ & 13 & 2.00 & 6.50 & 3.73 & 1.62 \\
\hline $\begin{array}{l}\text { Number of } \\
\text { exercise during } \\
\text { the off season (in } \\
\text { days) }\end{array}$ & 13 & 2.00 & 6.00 & 3.62 & 1.12 \\
\hline
\end{tabular}


Table D3. Average weight deviations for First 8 weeks

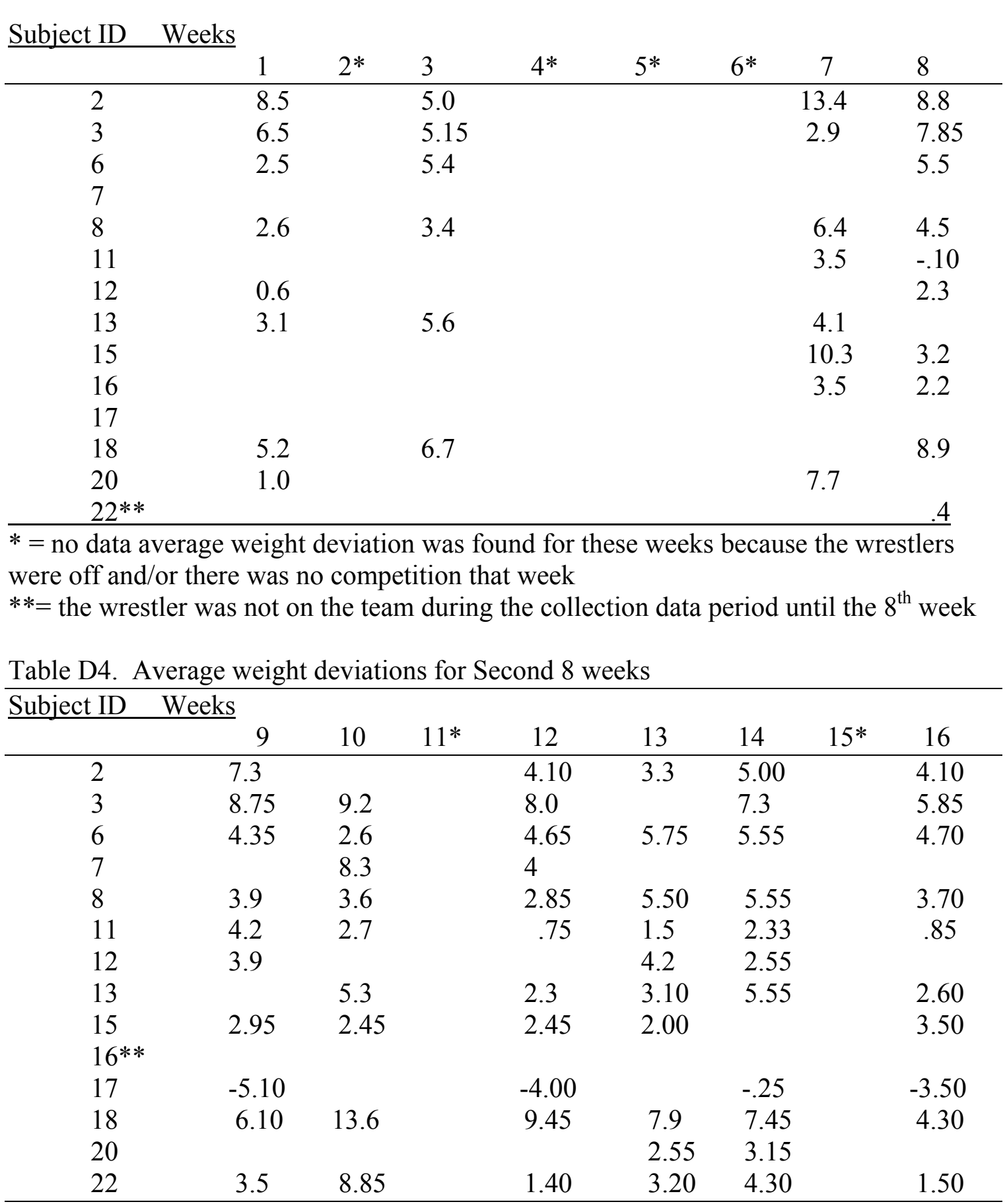

$*=$ no data average weight deviation was found for these weeks because the wrestlers were off and/or there was no competition that week, $* *=$ this wrestler was not on the team for this data collection period 


\section{APPENDIX E \\ RECOMMENDATIONS FOR FUTURE RESEARCH}

1. Increase the sample size of the subjects. When a Pearson's correlation and/or a t-test are performed there should be a sample size of 20 or more individuals to increase the statistical power. It is believed there is a higher possibility of a statistical significance with a higher power.

2. Weigh-ins should take place before and after practices. Both the NCAA and the ACSM recommend weigh-ins occur at both times so the researcher can account for water loss. The study only performed weigh-ins after practice so no water loss was measured. 3. The athlete's diet should be examined more closely during the course of the study. A diet high in carbohydrate has been suggested to enable the athlete to have better performance rates in areas of strength, power, and endurance than the athlete with a normal or lower carbohydrate diet.

4. Adding subjects from other colleges may be beneficial. This may help support the NCAA certification route as becoming safer for the athlete.

5. More stringent guidelines about inclusion/exclusion criteria should be included in a different study.

6. Subjects should be interviewed at weekly intervals to obtain perceptions of what how they feel. This would aid the researcher in perceptions of recovery and over-training. 7. Subjects could be examined on mood states during periods of RWL. There are many surveys investigators could administer to the subjects that allow a quantitative analysis to be performed and then correlated to RWL. 


\section{ADDITIONAL REFERENCES}

36. Taber's cyclopedic medical dictionary.F.A. Davis Co. Philadelphia. 2001. Donal Venes Ed. $19^{\text {th }}$ ed. 677.

37. Utter A, O'Bryant H, Haff G, Trone G. Physiological profile of an elite freestyle wrestler preparing for competition: a case study. J Strength Cond Res. 2002;16(2):308-315.

38. Davis S, Dwyer G, Reed K, Bopp C, Stosic J, Shepanski M. Preliminary investigation: the impact of the NCAA wrestling weight certification program on weight cutting. J Strength Cond Res. 2002;16(2):305-307.

39. CRS. Wrestling with weight cycling. Phys Sports Med. 1992;20(7):24.

40. Boden B, Lin W, Young M, Mueller F. Catastrophic injuries in wrestlers. Am J Sports Med. 2002;30(6);791-795.

41. Roemmich J, Sinning W. Weight loss and wrestling training: effects on nutrition, growth, maturation, body composition, and strength. J Appl Physiol. 1997;82:17511759.

42. Uhl D. Weight loss in wrestlers: considerations for high school strength and conditioning coaches. Strength Cond J. 2001;23(6):53-54.

43. Lathrop SE, Brunet ME, Gansneder BM, Shultz SJ. Evaluation of eating behaviors and attitudes in athletes using the EAT - 26. J Athl Train Supp. 2003;38(2):S-43.

44. Nagle FJ, Morgan WP, Hellickson RO, Serfass RC, Alexander JF. Spotting success trials in olympic contenders. Phys. Sports Med. 1975;3:31-34.

45. Saltin B. Circulatory response to submaximal and maximal exercise after thermal dehydration. J Appl Physiol. 1964;19;1125-1132.

46. Yankanich J, Kenney L, Fleck S, Kraemer W. Precompetition weight loss and changes in vascular fluid volume in NCAA division I college wrestlers. J Strength Cond Res. 1998;12(3):138-145.

47. Webster S, Rutt R, Weltman A. Physiological effects of a weight loss regimen practiced by college wrestlers. Med Sci Sports Exerc. 1990;22(2):229-234.

48. Caldwell JE, Ahonen E, Nousiainen V. Differential effects of sauna-diuretic-and exercise induced hypoydration. J Appl Physiol. 1984;54:1018-1023.

49. Yoon J. Physiological profiles of elite senior wrestlers. Sports Med. 2002;32(4):225233. 
50. Steen S, Oppliger R, Brownell K. Metabolic effects of repeated weight loss and regain in adolescent wrestlers. JAMA. 1988;26(1):47-50.

51. Ahlman K, Karvonen MJ. Weight reduction by swetating in wrestlers, and it's effect on physical fitness. J Sports Med Phys Fitness. 1961;1:58-62

52. Bosco JS, Terjung RL, Greenleaf JE. Effects of progressive hypohydration on maximal isometric muscular strength. J Sports Med Phys Fitness. 1968;8:81-86.

53. American College of Sports Medicine. Weight loss in wrestlers (position stand). Med Sci Sports Exerc. 1996;28:ix-xii.

54. Schnirring L. NCAA strengthens weight-cutting rules. Phys Sports Med. 1998;26(7):16.

55. National Collegiate Athletic Association. 2003 NCAA wrestling rules and regulations. 2003;WA-28-WA-29. 